GLOBAL WATER PATHOGEN PROJECT

PART THREE. SPECIFIC EXCRETED PATHOGENS: ENVIRONMENTAL AND EPIDEMIOLOGY ASPECTS

\title{
TRICHURIS TRICHIURA
}

\section{Ricardo Izurieta}

University of South Florida

Tampa, United States

Miguel Reina-Ortiz

University of South Florida

Tampa, United States

Tatiana Ochoa-Capello

Moffitt Cancer Center

Tampa, United States 


\section{Copyright:}

\section{cc) (1) (2) \\ BY SA}

This publication is available in Open Access under the Attribution-ShareAlike 3.0 IGO (CC-BY-SA 3.0 IGO) license (http://creativecommons.org/licenses/by-sa/3.0/igo). By using the content of this publication, the users accept to be bound by the terms of use of the UNESCO Open Access Repository (http://www.unesco.org/openaccess/terms-use-ccbysa-en).

\section{Disclaimer:}

The designations employed and the presentation of material throughout this publication do not imply the expression of any opinion whatsoever on the part of UNESCO concerning the legal status of any country, territory, city or area or of its authorities, or concerning the delimitation of its frontiers or boundaries. The ideas and opinions expressed in this publication are those of the authors; they are not necessarily those of UNESCO and do not commit the Organization.

\section{Citation:}

Izurieta, R., Reina-Ortiz, M. and Ochoa-Capello, T. (2018). Trichuris trichiura. In: J.B. Rose and B. Jiménez-Cisneros (eds), Water and Sanitation for the 21st Century: Health and Microbiological Aspects of Excreta and Wastewater Management (Global Water Pathogen Project). (L. Robertson (eds), Part 3: Specific Excreted Pathogens: Environmental and Epidemiology Aspects - Section 4: Helminths), Michigan State University, E. Lansing, MI, UNESCO. https://doi.org/10.14321/waterpathogens.43

Acknowledgements: K.R.L. Young, Project Design editor; Website Design (http://www.agroknow.com)

Last published: August 3, 2018 


\section{Summary}

Trichuris trichiura is a metazoan parasite in the group of geohelminths, which means that transmission of eggs is often from contaminated soil. Gravid Trichuris trichiura females lay 3,000-20,000 unembryonated eggs every day that are excreted in the host feces. Humans are the only known hosts of T. trichiura. Following excretion, fertilised Trichuris eggs will mature into an embryonated infective stage, which, if consumed by a susceptible person will establish a new cycle of infection. Worldwide it has been estimated that 600-800 million persons are infected by this nematode. Nevertheless, this may be a conservative estimate as just $10 \%$ of infected subjects present symptoms. Level of infestation and susceptibility may also vary based on predisposing genetic factors in the human host. School-age children show higher prevalences, most likely due to increased exposure to contaminated soil and partial natural immune protection after repetitive exposures. Genetic predisposition has been reported in some populations.

Clinical manifestations vary and depend on the degree of infection. Light infections are usually asymptomatic, whereas heavy infections may manifest with watery, mucusladen, bloody, painful diarrhea, which may progress into anemia and growth retardation if not treated. Rectal prolapse is also associated with heavy infections. Diagnosis is made by microscopic examination of stool samples and identification of unembryonated eggs. Trichuriasis is effectively treated with albendazole and alternative treatments include mebendazole, levamisole, ivermectine and pyrantel.

Warm, damp soil provides the best medium for egg development and transmission, and although there may be some transmission in temperate areas, in tropical areas hyperendemic transmission may occur. Water may be vehicle of transmission when it is contaminated by ova previously embryonated in soil or mud. Consequently, water containing embryonated ova, as well as vegetables irrigated with sewage or sewage effluent, may act as vehicles of transmission.

Preventive measures at the primary level include proper sanitation, safe water, and food safety. Inactivation of embryonated ova by the use of urea and solar heat in biowaste has been proposed to inactivate ova. Education in hygienic practices is complementary to water and sanitation. In the secondary level of prevention, mass chemotherapy among school age children has been highly successful in its control, but due to heavy environmental contamination may only provide a temporary reprieve before reinfection.

Geohelminths, also known as soil-transmitted helminths (STHs), are metazoan parasites that require soil to complete their life cycle (Guerrant et al., 2011). Trichuris trichiura is the second most common geohelminth in the world (Pullan et al., 2014); although this may be changing since T. trichiura has become the most prevalent STH, at least in some regions of the world (Yu et al., 2016; AlMekhlafi et al., 2006; Norhayati et al., 1997). Other members in this classification include Ascaris lumbricoides, Ancylostoma duodenale and Necator americanus (Pullan et al., 2014). Because of this geographic and demographic distribution, trichuriasis is classified as a Neglected Tropical Disease (NTD) (Mackey et al., 2014). Neglected Tropical Diseases are a group of conditions that are highly prevalent among impoverished and marginalized tropical populations (Fitzpatrick and Engels, 2016; Mackey et al., 2014) and for which there is insufficient funding to either conduct proper research or to implement appropriate elimination and control strategies (Mackey et al., 2014).

Trichuriasis, the disease caused by the colonization and infestation of the human intestine with whipworms, is widely distributed worldwide with higher prevalence in usually impoverished tropical and subtropical regions (Guerrant et al., 2011). Trichuris spp. eggs are excreted in feces, end up in sewage but they need soil or soil-like storage conditions (e.g. like in sludge) to achieve its infective embryonated stage.

\subsection{Epidemiology of the Disease and Pathogen(s)}

\subsection{Global Burden of Disease}

Trichuris trichiura has a worldwide distribution (Figure 1). Along with Ascaris lumbricoides and hookworms, Trichuris trichiura is one of the three most prevalent STHs in the world (Cooper et al., 2011). It is estimated that more than two billion people in the world are infected with at least one of these soil-transmitted helminths (WHO, 2016; Savioli et al., 2005; Pullan et al., 2014). Nevertheless, this may be a conservative estimate considering that only $10 \%$ or less of infected people present symptoms (Guerrant et al., 2011). In fact, some authors have suggested that the underestimation of $T$. trichiura is related to these four factors: 1) most people harbor low intensity infections which are asymptomatic; 2) it usually is found as one agent within a multi-agent contamination; 3) symptoms onset is particularly slow which may lead to lack of awareness among family members; and, 4) Trichuris produces disease in children rather than adults (Guerrant et al., 2011). In addition, the level of infestation and susceptibility may also vary based on predisposing genetic factors in the human host (Williams-Blangero et al., 2008). Early studies had suggested that a genetic component was responsible for some of the predisposition to trichuriasis (i.e. for $28-36 \%$ on the egg count variation) as evidenced both by: 1) higher levels of trichuriasis among the population in the Jishan Island (China) as compared to the Jirel population in Nepal; and, 2) by the high household egg count correlation among relatives with lack of household correlation among nonrelatives (Williams-Blangero et al., 2002). Subsequently, researchers provided evidence that 2 quantitative trait loci on chromosomes 9 and 18 may be responsible for the susceptibility to $T$. trichiura infection in some genetically predisposed individuals from a Tibeto-Burman ethnic group (i.e. the Jirel population in Nepal) (Williams-Blangero et al., 2008). 


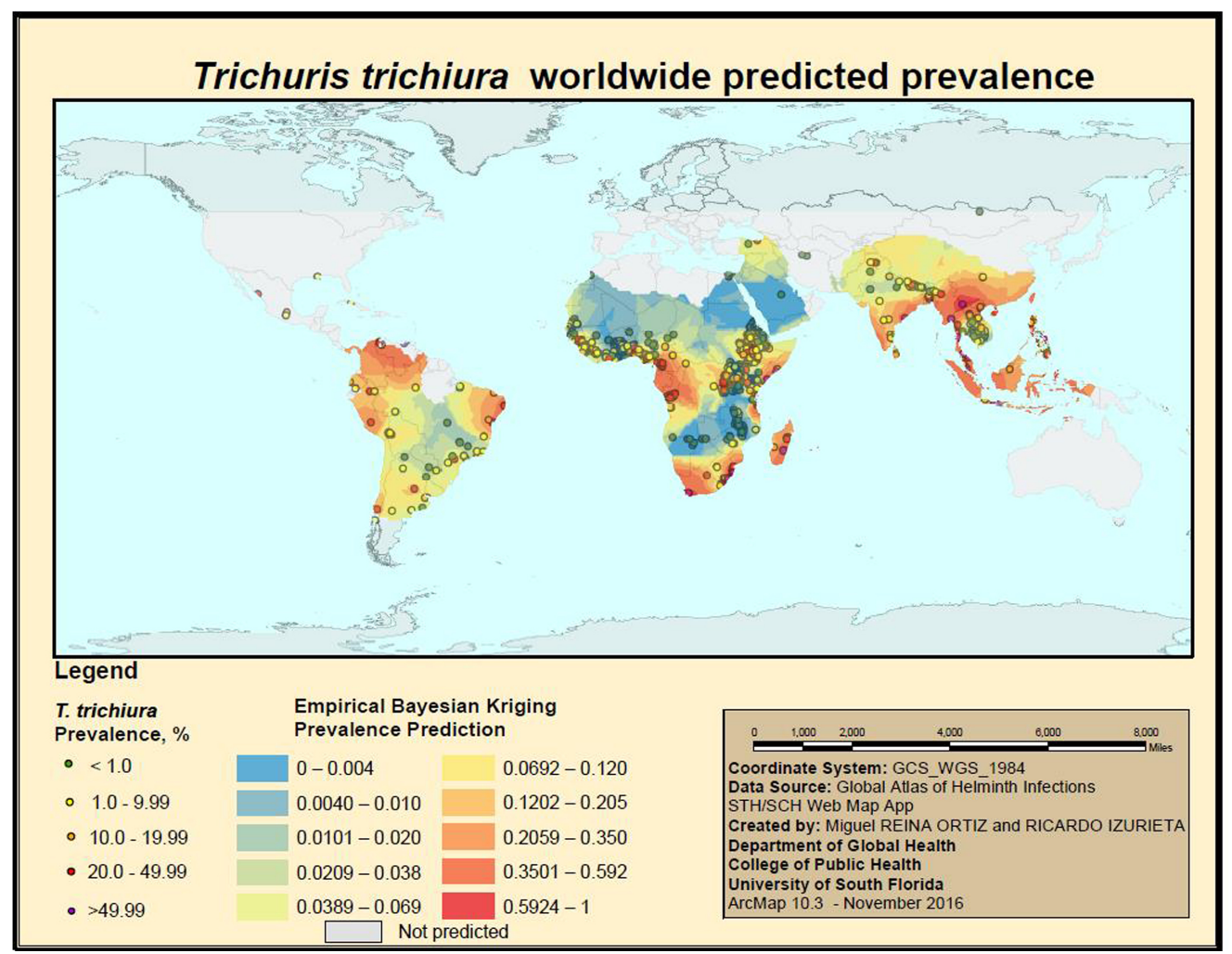

Figure 1. Worldwide Prediction of Trichuris trichiura Prevalence, 2014. Data source: Global Atlas of Helminth Infections. STH/SCH Web Map App.

Worldwide, Ascaris lumbricoides continues to be the most prevalent STH infecting an estimated 683 to 861 million people compared to 427 to 503 million cases of trichuriasis during 2015 (Disease et al., 2016). However, in the Americas, Trichuris trichiura has replaced Ascaris lumbricoides as the most prevalent STH with 100 million inhabitants infected with the former compared to just 84 million people infected with the latter (Bethony et al., 2006). Similarly, Trichuris trichiura prevalence is higher than that of A. lumbricoides both in the East and Southern Sub-Saharan Africa (SSA) regions (Pullan et al., 2014). It is estimated that 42.2 million cases of Trichuris trichiura occur in the East SSA Region compared to 34.4 million cases of Ascaris lumbricoides whereas in the Southern Region Trichuris trichiura is the most prevalent STH and accounts for 23.3 million cases versus 8.6 million cases of Ascaris lumbricoides (Pullan et al., 2014). In countries like Malaysia, Trichuris trichiura is the most common STH representing $57 \%$ of all helminthic infections among indigenous tribes followed by Ascaris lumbricoides with 24\% (Anuar et al., 2014). Although this may be a result of the successful school-based deworming activities in addition to improvements in water and sanitation, it may also be an indication of the development resistance to benzimidazole anthelminthic drugs in Trichuris trichiura parasites. Additionally, albendazole-only, ivermectindeficient therapeutic regimes might not be effective in clearing Trichuris trichiura (Hotez, 2009).

\subsubsection{Global distribution}

Trichuris trichiura is distributed worldwide with areas of hyper-endemicity located in tropical zones. Geographicinformation systems (GIS) are increasingly finding application in global public health research. GIS-based analyses have successfully been conducted in a wide range of communicable diseases. This novel tool has the potential to detect and characterize geographic areas with soil characteristics propitious for an intense STH transmission and then predict and identify other unknown areas that may favor parasite growth and development.

\subsubsection{Groups at risk}

People living in tropical and subtropical areas of the world are at highest risk of infection by $T$. trichiura; however, populations without reliable access to safe water and sanitation elsewhere are also at increased risk of infection (Guerrant et al., 2011). The observed increased incidence of this parasite in warm areas of the world may be associated with the capacity of the ova to continue its development in soil under favorable temperatures (usually between 28 and $35^{\circ} \mathrm{C}$ ) until it reaches its infective stage (Moe and Izurieta, 2003). As a matter of fact, it has been previously reported that helminths' ova can stop its development in the environment if they do not find favorable temperature and moisture conditions (Manser et al., 2015).

Trichuriasis is a disease that most commonly affects 
school-age children, (Bethony et al., 2006) who show higher prevalence (Yu et al., 2016; Bethony et al., 2006; Corrales et al., 2006) most likely due to increased exposure to contaminated soil and partial natural immune protection after repetitive exposures (Bethony et al., 2006). Since the disease is rarely severe among adults and since it is widely distributed among impoverished populations in the rural tropics, it is considered to be an NTD, as explained earlier. Among children, chronic and/or repetitive trichuriasis may lead to school impairment, cognitive developmental challenges, poorer performance, and height and weight impairment, among others (Williams-Blangero et al., 2008).

\subsubsection{Symptomatology}

Clinical manifestations of trichuriasis vary and depend on the degree of infection (Bethony et al., 2006). Light infections are usually asymptomatic whereas heavy infections may manifest with watery, mucus-laden, bloody, painful diarrhea, which may progress into anemia and growth retardation if not treated (Bethony et al., 2006; Guerrant et al., 2011). In severe cases, a mucopurulent dysenteric diarrhea may be accompanied by rectal prolapse, as shown in Figure 2 (Jung and Beaver, 1951). There is usually no eosinophilia. In severe pediatric cases, digital clubbing, hypoproteinemia, severe anemia and evident growth retardation are present (Cook and Zumla, 2003).

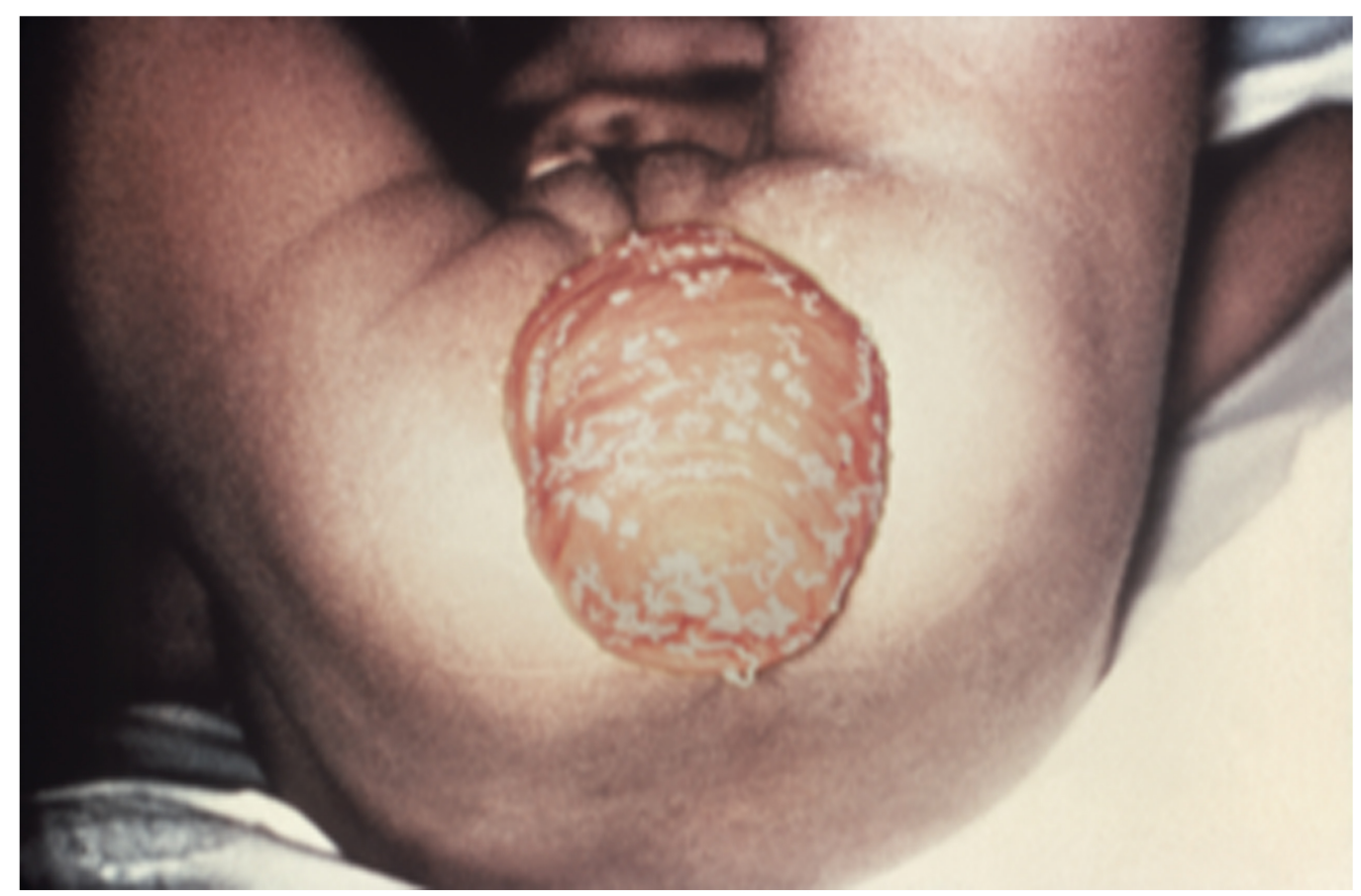

Figure 2. Rectal prolapse caused for massive Trichuris trichiura infestation. Centers for Disease Control and Prevention. Public Health Image Library - PHIL 13370. Atlanta, GA - USA. https://phil.cdc.gov/Details.aspx?pid=13370

\subsection{Taxonomic Classification of the Agent}

Trichuris trichiura is a nematode that belongs to the Trichocephalida order (Myers and Espinosa, 2017) and, therefore, it is related to Trichinella spiralis. A more detailed taxonomic classification of this nematode is offered in Table 1. As shown in Table 1, Trichuris trichiura is classified within the Trichuris genus, a genus that has a complex and controversial species-level classification and which was first reviewed by Dujardin in 1845 (Callejon et al., 2015). Several species have been described, specially among ruminants, many with ability to infect more than one host (Callejon et al., 2015). By 1974, more than 23 ruminant Trichuris species were described by Knight (Callejon et al., 2015). Trichuris species differentiation and classification is extremely complex, to say the least, and different approaches have been used including physical differentiation (i.e. based on spicule sheath, spicule length, the spines in the spicule sheath, vulvar structure, presence or absence of vulvar spines, vaginal shape, length and structure), electronic microscopic differences, isoenzymatic analysis, molecular techniques, genetic sequencing, etc. (Callejon et al., 2015; Ketzis, 2015). 
Table 1. Taxonomic classification of Trichuris trichiura. Data Source: University of Michigan's Museum of Zoology (http://animaldiversity.org/accounts/Trichuris_trichiura/classification)

\begin{tabular}{lcc}
\hline & Taxonomic Level & Classification \\
\hline Domain & Eukarya \\
Kingdom & Animalia \\
Phylum & Nematoda \\
Class & Adenophorea \\
Subclass & Enoplia \\
Order & Trichocephalida \\
Family & Trichuridae \\
Genus & Trichuris \\
Species & trichiura
\end{tabular}

Many other species of Trichuris have been found to infect other mammals, including: T. campunala and $T$. serrata in cats (Ketzis, 2015),T. globulosa in camels (Callejon et al., 2015), T. tenuis in camelids, T. ovis and T. skrjabini in sheep (Callejon et al., 2015), Trichuris discolor in cows, Trichuris ovis in sheep and goats, and Trichuris leporis in rabbits (Faust, 1949). Consequently, the detection of Trichuris spp. ova in soil, sludge, or biosolids can be associated with its contamination with feces from humans or from any of the other mammals that can be infected by a trichurid parasite.

\subsubsection{Physical description of the agent}

\subsubsection{Trichuris trichiura}

Trichuris trichiura exists in two main life cycle stages: eggs and adults, with larvae representing the intermediate phase between eggs and adults.

\subsection{Ova}

Trichuris trichiura thick-walled, barrel-shaped eggs are yellow to brown in color (Figure 3 ) and relatively small when compared to other human nematodes ( $T$. trichiura eggs are $54 \mu \mathrm{m}$ in length and $22 \mu \mathrm{m}$ in width: range 49-65 $\mu \mathrm{m}$ and 20-29 $\mu \mathrm{m}$, respectively) (CDC, 2016; Guerrant et al., 2011). One important morphologic characteristic of $T$. trichiura eggs is the presence of a polar mucoid "plug" at each extreme, although in rare occasions atypical eggs lacking these plugs may be found (CDC, 2016).Trichuris trichiura eggs may depart from their ellipsoidal shape and become thinner or fatter. The embryo within the eggs may be found in any of the following developmental stages: underdeveloped, partially developed, fully developed or death stage (Price, 1994).

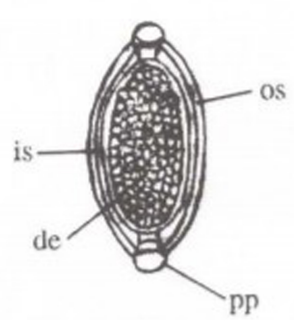

$$
\begin{aligned}
& \text { os = outer shell } \\
& \text { is }- \text { inner shell } \\
& \text { de = developing embryo } \\
& \text { pp = polar plugs }
\end{aligned}
$$

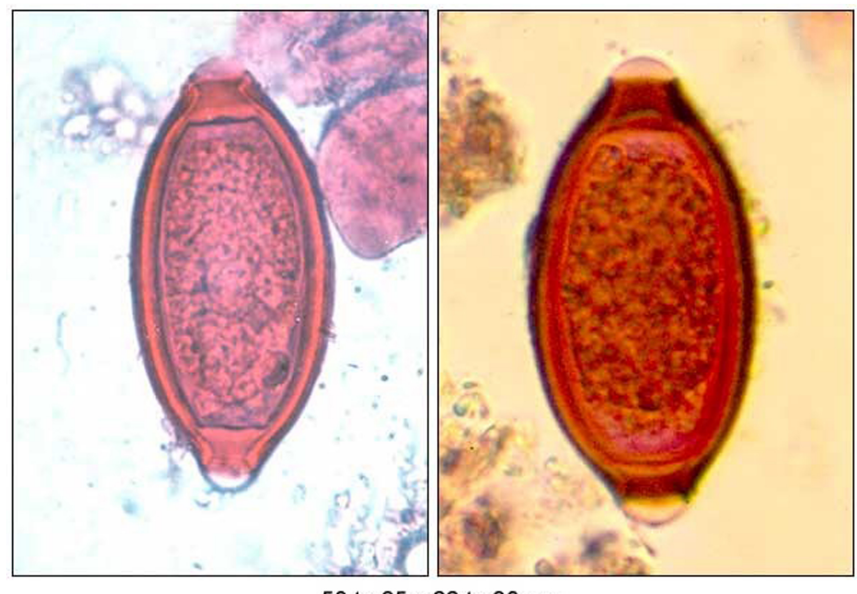

50 to $65 \times 22$ to $30 \mu \mathrm{m}$

Figure 3. Trichuris trichiura ova structure. (Courtesy of University of South Florida Donald Price Center) 


\subsection{Adult parasites}

The adult parasite is shaped like a whip, hence its common name: whipworm (Guerrant et al., 2011). The adult parasite is 40 to $45 \mathrm{~mm}$ length in the male and 30 to $35 \mathrm{~mm}$ length in the female, and shows a greyish-white often slightly pink color. Adult Trichuris parasites display a hair-like structure in their heads; however, it was originally described as being located in their tails and therefore the name Trichuris where tricho means hair and uris means tail (Guerrant et al., 2011). The finer part of the whip is the anterior end (also called stichosome) whereas the wider part (i.e. the handle of the whip) corresponds to the posterior end (Guerrant et al., 2011). The posterior end hosts the reproductive organs and the intestine whereas the pharynx is found in the anterior part (Guerrant et al., 2011). Among males, the cellular esophagus is half as long as the posterior end, which is has a caudal extremity 360 degrees coiled and hosts the testis, ejaculatory duct, spicule and cloaca. The female parasite has half of the posterior portion occupied by a stout uterus full of eggs (Price, 1994). In cases when the infection is untreated, the worm can live between 4 to 8 years in the host (Markell et al., 1999).

\subsubsection{Other trichurid nematodes}

Ova of Trichuris vulpis, a parasite of dogs that can mature in humans, can be differentiated from that of Trichuris trichiura because of its larger size (70 to $80 \times 25$ to $30 \mu \mathrm{m}$ ) (Figure 4) (Gorbach et al.,1992; Price, 1994). The ova of Trichuris suis, the trichurid species that infects pigs, are similar to the ova of Trichuris trichiura and they can also infect humans (Cook and Zumla, 2003). As a matter of fact, an increase incidence of this parasite has been observed in semirural households, which practice pig farming (Corrales et al., 2006).

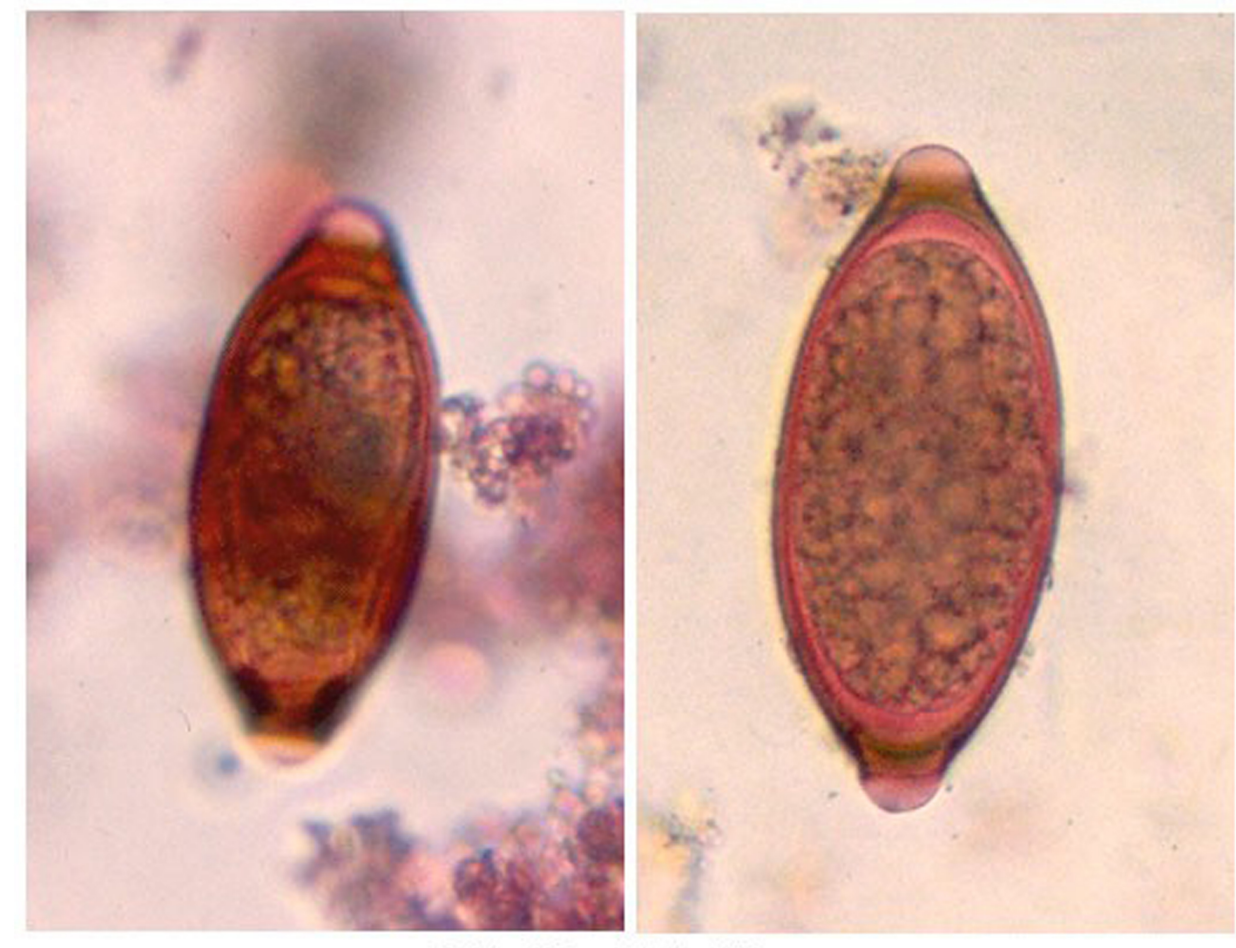

70 to $88 \times 25$ to $30 \mu \mathrm{m}$

\section{Figure 4. Trichuris vulpis ova structure (Courtesy of University of South Florida Donald Price Center)}

\subsubsection{Tissue tropism/cellular receptors/latency}

Trichuris trichiura and other trichurid parasites induce a Th2 immune response. This characteristic has led to the experimental use of Trichuris suis ova for the treatment of Crohn's disease in humans (a condition which is characterized by a strong Th1 response) (Summers et al., 2005; Weinstock and Elliott, 2009). The rationale for this approach lies in the fact that Th1 and Th2 immune responses are counterbalancing arista of the immune system (Wright et al., 2009). Although Th2 responses have clearly been associated with Trichuris trichiura, recent reports suggest that chronic and/or heavy geohelminth infections may lead to a dampened, regulated immune response that has been called modified Th2 response (Figueiredo et al., 2010). Modified Th2 responses had previously been described with high-level exposure to allergens, specially cat allergens (Platts-Mills et al., 2001). It seems, that there exist a self-regulating mechanism through which the immune system balances out the harmful inflammatory Th2 responses should an immunogen be present in excess quantity or time. Similarly, recent studies suggest that chronic/heavy infections with geohelminths may lead to a modified Th2-like response (Reina-Ortiz et al., 2011); which, in theory, would have a protective effect. Modified Th2 responses are characterized by a cytokine pattern typical of a Th2 response (i.e. abundant IL-4) with the addition of the immunomodulatory IL-10 cytokine (Sanchez et al., 2015; Platts-Mills et al., 2001). 


\subsection{Transmission}

\subsubsection{Life cycle}

\subsubsection{1 in the human and animal host}

Adult female T. trichiura dwell in the mucosal crypts of the cecum and lay between 2,000 and 20,000 unembryonated eggs (Urquhart et al., 1988; Guerrant et al., 2011). The number of ova per worm excreted in feces is in inverse relation to the number of worms (Bundy and Cooper, 1990). Soil contamination with geohelminth eggs is an essential step in the chain of infection. In the soil, eggs need to mature or embryonate, a process that takes between 15 and 30 days (i.e. 2-4 weeks) (Guerrant et al., 2011), a timeframe that varies according to environmental conditions (Tun et al., 2015). Soil egg maturation is a sequential process during which Trichuris trichiura evolves from unembryonated egg into a 2-cell stage, then into advanced cleavage stage and, finally, into infective embryonated eggs which will continue the life cycle in a human host if ingested. Larvae in stage L1 are found within embryonated T. trichiura eggs (Guerrant et al., 2011). After ingestion, larvae will be released from embryonated eggs, hatching in the small intestine. It has been suggested that this step is at least partially regulated or induced by the presence of intestinal microbiota (Giacomin et al., 2015). Larvae will mature through 4 phases (i.e. up to L4 stage larvae) to develop into large intestine-dwelling adults (both male and female), which will reside in either the cecum and/or the ascending colon (Guerrant et al., 2011). In this habitat, T. trichiura inserts its stichosome into the cryptal epithelium whereas the posterior end floats freely in the intestinal lumen (Guerrant et al., 2011). Sixty to seventy days after infection, females start laying eggs and the cycle repeats itself. Adult Trichuris trichiura may live for up to 1-3 years (Guerrant et al., 2011). A summary of the life cycle is offered in Figure 5. 


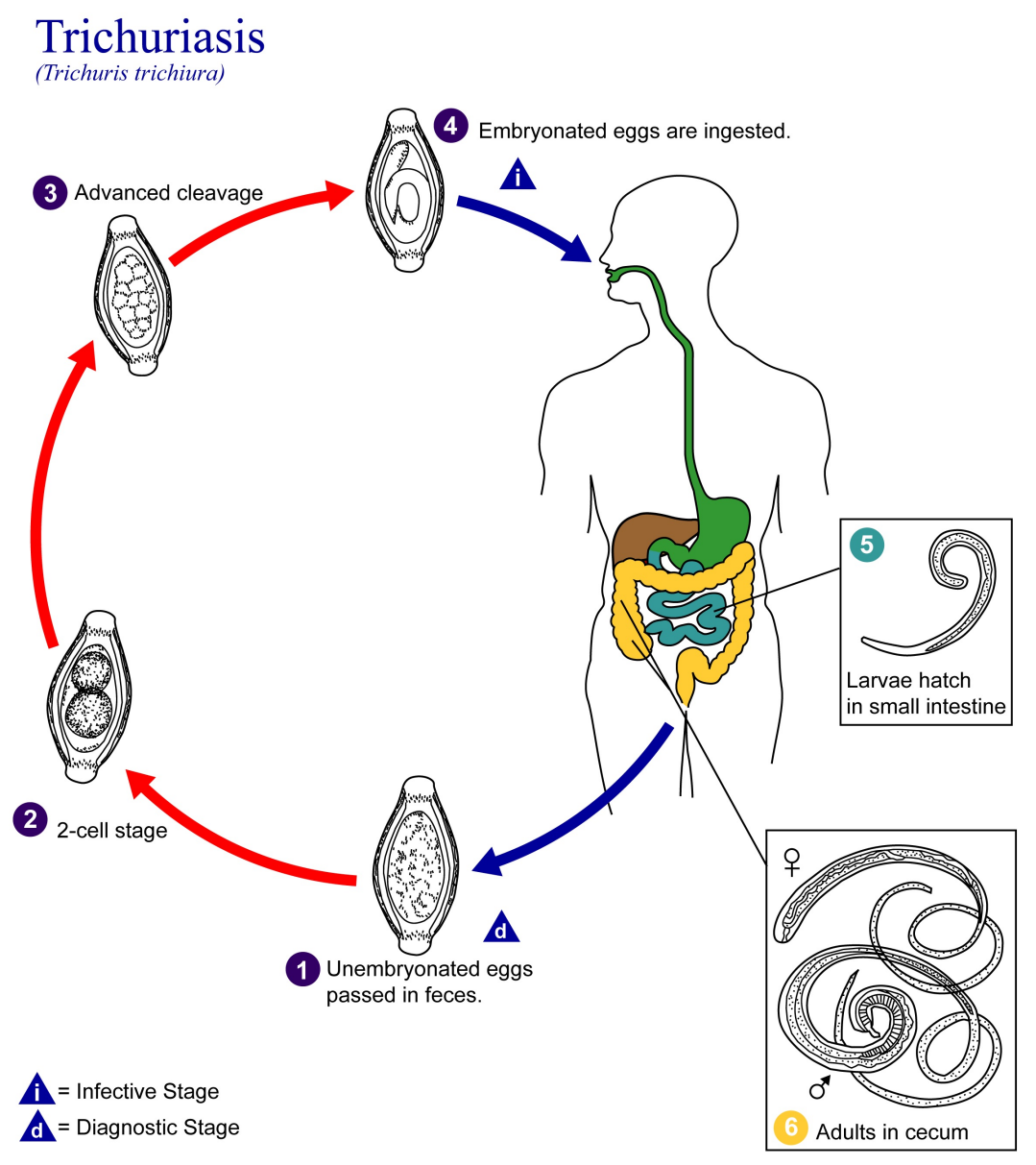

Figure 5. Trichuris trichiura life cycle. Source: da Silva and Moser, 2002. This is an illustration of the life cycle of Trichuris trichiura, the causal agent of Trichuriasis. Public Health Image Library - PHIL 3424. Centers for Disease Control and Prevention. Atlanta, GA - USA. https://phil.cdc.gov/Details.aspx?pid=3424

\subsubsection{In the environment}

As explained earlier, soil egg maturation is a sequential process during which Trichuris trichiura evolves from unembryonated egg into embryonated eggs, which will continue the life cycle in a human host, if ingested. Detailed survival conditions and development of eggs in the environment are described in section 2.0 Occurrence in the Environment.

\subsubsection{Hosts and reservoirs}

Soil is a reservoir for all Trichuris species. Humans and non-primate animals such as pigs and dogs are reservoirs for Trichuris trichiura, Trichuris suis and Trichuris vulpis, respectively. Trichuris spp. are helminths that infect the ceca and colons of a variety of mammalian species including anthropoids, swine and canine. Trichuris trichiura parasitizes human and nonhuman anthropoids (Kuntz and Meyers,1966; Melfi and Poyser, 2007). In fact, Trichuris trichiura is easily transmitted between human and nonhuman primates including monkeys and lemurs
(Stephenson et al., 2000). More specifically, T. trichiura has been reported in Colobus ruformitratus and Cercopitheccus diana monkeys (Faust, 1949). Therefore, it should be classified as an anthropozoonosis with important impact in human/public health.

\subsubsection{Animal hosts}

It has been previously suggested that stray cats and dogs may serve as important sources of environmental contamination for helminth infections (Tun et al., 2015). In fact, a study conducted in Malaysia revealed that $87.7 \%$ of stray dogs and $57.9 \%$ of stray cats were found to harbor a helminth infection with $8.4 \%$ of those infections being caused by Trichuris spp. (Tun et al., 2015). This level of infection may hold a public health relevance given the fact that stray cats and dogs tend to defecate within an urban/human environment increasing risk of infection to other healthy animals (i.e. mascots) or even humans (Tun et al., 2015). The same study by Tun et al. (2015) revealed that $23 \%$ of soil samples from recreational parks and other frequently visited locations such as bus stops, night 
markets, streets and children's playgrounds were infected with helminth eggs.

\subsubsection{Pathogenesis and immunity}

There are numerous pathogen- and host-derived molecules that play an important role in the pathogenesis of, and subsequent immune responses to, Trichuris trichiura infections. Serine-proteases are a family of ubiquitous multifunctional, multiorganism proteins that are believed to be involved in the pathogenesis of parasitic helminths, among other functions, contributing as crucial factors for the successful colonization/establishment of an infection (Yang et al., 2015). Specifically, Trichuris muris, the mice trichurid parasite, expresses two major collagenspecific serine peptidases (i.e. serine peptidases with activity against collagen-like molecules) which are believed to be involved in the host tissue invasion process including the development and maintenance of the parasite's characteristic muco-syncytial habitats as well as the penetration or integrity disruption of epithelial cell membranes (Yang et al., 2015). Moreover, it has been suggested that $T$. muris-derived serine proteases can cleave Muc2, a major intestinal mucin, leading to mucin network disassembly and, therefore, to impaired mucus layer production which may translate in lower probability of parasite expulsion (Yang et al., 2015). Another putative function of this serine-protease would be the creation of an environment conducive to mating and egg laying (Yang et al., 2015).

Upon helminth infection, host immune responses are triggered to get rid off the infection. Typically, acute helminth infections are followed by strong, inflammatory Th2 responses that are characterized by an IL-4 lead immune environment. In fact, Trichuris trichiura infections have been associated with Th2 immune responses (Giacomin et al., 2015). However, it has been hypothesized that chronic infections might lead to a dampened version of this Th2 response that would aim at targeting the parasite while preventing the harmful effects that chronic inflammation may have on the hosts tissues. Such response has been labeled as modified Th2 response and is characterized by increased IL-10 levels in the context of the high IL-4 Th2 response. Modified Th2 responses have been observed in other circumstances of chronic exposure to Th2-inducing antigens, like cat-derived allergens (PlattsMills et al., 2001). Similarly, recent studies have suggested that such Modified Th2 response might be evoked not only during chronic but also in heavy infections, which may also elicit a harmful, strong Th2 response (Reina-Ortiz et al., 2011).

Interestingly, Th2 responses are believed to downregulate Th1 and Th17 immune responses, which in turn are associated with inflammatory bowel disease (Giacomin et al., 2015). Helminth-related inflammation suppression is not an exclusive characteristic of Trichuris trichiura but rather a more widely observed phenomenon. Although the mechanisms leading to this suppression are not well understood and may include the induction of modified Th2 responses as discussed above, other pathways have been suggested including a putative helminth-induced microbiota modification (Giacomin et al., 2015). These suppressive characteristics have been argued to be an important factor to consider the potential therapeutic benefits of helminths, specially to treat human intestinal inflammatory diseases such as inflammatory bowel disease or coeliac disease (Giacomin et al., 2015). Experimental data supports this hypothesis. For instance, Heligmosomoides polygyrus bakeri infection lead to increased lactobacilli and improved outcomes among IBD suffering mice whereas TSO administration lead to reduced Fibrobacter and Rumicoccus with a concomitant increase in Campylobacter in pigs (Giacomin et al., 2015). Similarly, Trichuris trichiura administration to idiopathic chronic diarrhea (ICD)-diseased macaques lead to reduced cyanobacteria with increased bacterial diversity including rise in Bacteroidetes and Tenericutes (Giacomin et al., 2015). Interestingly, Trichuris treatment affected bacterial attachment which suggests that whipworm infection might have a role in mucosal healing (Giacomin et al., 2015).

Other mechanisms of immune regulation associated with whipworm infection include following: Interferon gamma and interleukin (IL) 17 suppression, increased type 2 cytokine production, regulatory $\mathrm{T}$ cell and immunomodulatory cytokine (i.e. IL-10, IL-22, Transforming Growth Factor - beta) induction, and recruitment of alternatively activated macrophages, dendritic cells and $B$ cells (Giacomin et al., 2015).

\subsubsection{Other trichurid nematodes}

\subsubsection{Trichuris suis}

Trichuris suis is the porcine whipworm. Pigs and wild boars are the natural host for Trichuris suis, a parasite that can also affect other species - including transient, asymptomatic infections in humans (Nejsum et al., 2012; Giacomin et al., 2015). Humans probably become infected with $T$. suis by ingesting contaminated soil or water. Due to this double benefit (i.e. transient asymptomatic infections leading to inflammation suppressive immune responses), Trichuris suis ova (TSO) have been tried as a therapeutic solution for Crohn's disease, ulcerative colitis and multiple sclerosis (Giacomin et al., 2015). T. suis is found worldwide, but is most prevalent in warm, humid climate whereas it is rare or nonexistent in arid, very hot, or very cold regions (The Center for Food Security and Public Health, 2005). T. suis adults survive in pigs for approximately 4 to 5 months.

\subsubsection{Trichuris vulpis}

Trichuris vulpis are the canine trichurid species. Although T. vulpis may be found worldwide, these parasites are most prevalent in warm and humid zones, similar to observed distribution of Trichuris trichiura. Similar to $T$. suis, T. vulpis are rarely found or are nonexistent in arid, very hot, or very cold regions. Human cases of T. vulpis have already been reported as early as 1956 (Hall and Sonnenberg,1956) and this parasite should also be considered a zoonotic disease for man (Kagei et al., 1986). 
T. vulpis-associated diarrhea has been reported among slum-dwelling children of India (Mirdha et al., 1988), an occurrence that might be common in other overcrowded urban locations, (Stephenson et al., 2000) whereas epistaxis and abdominal discomfort were reported in a 9 years old girl from Mexico (Marquez-Navarro et al., 2012). Additional human cases have been suspected or reported in Italy (De Carneri et al., 1971), Poland (Lineburg and Jastrzebski, 1987) and the United States (Dunn et al., 2002). T. vulpis adults survive in dogs for approximately 16 months (The Center for Food Security and Public Health, 2005). A prevalence of up to $10 \%$ has been reported in both stray and cared-for dog populations in various countries (Robinson et al., 1989; Vanparijs et al., 1991). However, T. vulpis has not been a frequent laboratory report in human hosts, which may indicate a possible misclassification with Trichuris trichiura during coprology diagnosis.

\subsection{Population and Individual Control Measures}

\subsubsection{Vaccines}

There are two factors to consider in the development of a $T$. trichiura vaccine. First, the pick of prevalence of $T$. trichiura in school-age children (Yu et al., 2016; Bethony et al., 2006; Corrales et al., 2006) makes it plausible to propose the development of natural immune protection of children after various exposures to this parasite. Second, anthelminthic treatment of school-age populations is one of the main, if not the main, public health strategy implemented in the control of Trichuris trichiura and other helminths (Kepha et al., 2017). This therapeutic control of T. trichiura may prevent the development of active natural immunity and may lead to drug resistance. Consequently, the development of a $T$. trichiura vaccine, in addition to water and sanitation, can represent more sustainable interventions in the control of this parasite.

Various research teams are currently working in the identification of functional antigens against Trichuris muris. These preliminary studies may be the initial steps for the development of a Trichuris trichiura vaccine for humans (Dixon et al., 2008; Dixon et al., 2010). The most effective antigenic structures are the anterior (esophageal) region of the adult worm, although protection was apparent following vaccination with antigens prepared from other regions of adult worms and from whole larval worms (Wakelin and Selby, 1973; Dixon et al., 2008). Most recently, the development of a pan-anthelmintic vaccine against Ascaris lumbricoides, Trichuris trichiura and hookworms is on experimental phases at The Sabin Vaccine Institute Product Development Partnership (Zhan et al., 2014). Nevertheless, urticarial reactions upon receiving recombinant forms of such antigens have been reported (Diemert et al., 2012). These issues must be addressed since, at least for some antigens, it has been previously reported that allergic reactions may lead to life threatening anaphylactic reactions upon antigen re-exposure in susceptible individuals (Stratton et al., 1994).

\subsubsection{Hygiene measures}

There are several easy-to-implement, common hygiene practices that can be adopted to prevent Trichuris spp. transmission. In fact, access to water and hygiene sanitation have been identified as factors affecting STH transmission intensity (Kepha et al., 2017). Proper wash of hands, vegetables and fruits can reduce the risk of acquiring helminth infections. However, this practice may be insufficient if vegetables or fruits that are being consumed raw have already been contaminated by soil or wastewater in the environment. The double and strong chitin structure of helminth ova may render the application of chlorine useless (i.e. chlorine may not be effective for helminth ova inactivation) (Guadagnini et al., 2013).

\subsubsection{Diagnosis and treatment in humans}

Trichuris trichiura diagnosis in humans is made by microscopic examination of stool samples and identification of unembryonated eggs. Although T. trichiura eggs may be easily identified in a microscopic preparation given their particular morphologic characteristics (i.e. the usual presence of a "plug" at each end), sometimes eggs might be vertical or inclined in their orientation resulting in a more difficult observation. This inconvenience may easily be corrected by gently tapping the coverslip (CDC, 2016).

There are several techniques used for stool sample examination. The most widely used in clinical practice probably is fresh examination whereas the most useful for epidemiological surveys, based on their increased sensitivity, would include Kato-Katz and filtration/concentration techniques (Guerrant et al., 2011).

Treatment of Trichuris trichiura in humans have traditionally been accomplished through the use of benzimidazole derivatives. In fact, very often, Trichuriasis is effectively treated by $400 \mathrm{mg}$ of albendazole given orally as a single dose. Alternative treatments include mebendazole, levamisole, ivermectin and pyrantel. However, Mebendazole and Albendazole inefficacy for the treatment of infections with Trichuris trichiura has been confirmed in various studies (Levecke et al., 2014b; Bennett and Guyatt, 2000; Keiser and Utzinger, 2008; Speare et al., 2006). This resistance has led to the evaluation of new drugs or drug combinations against Trichuris trichiura including pyrantel/oxantel (Albonico et al., 2002), mebendazole/ivermectin (Knopp et al., 2010), oxantel, (Speich et al., 2014), and papaya cysteine proteinases (Levecke et al., 2014a).

\subsubsection{Mass drug therapy}

According to recent studies, it is expected that deworming campaigns with a single oral dose of mebendazole (500 mg) among school-age children could lead to a greater than $50 \%$ fecal egg count reduction (FECR) rate. These estimates are based on the results of six trials involving 5,830 school children in Brazil, Cambodia, Cameroon, Ethiopia, the United Republic of Tanzania, and Vietnam. Should FECR rates be lower than this level, 
potential development of drug resistance may be suspected (Levecke et al., 2014b).

\subsubsection{Management of contacts}

Preventive measures at the primary level include proper sanitation, safe water, and food safety. Inactivation of embryonated ova by the use of urea and solar heat in biowaste has been proposed to inactivate geohelminths ova (Sharad et al., 2012). Education in hygienic practices such as hands washing, thorough washing of vegetables, and proper cooking of foods potentially contaminated with embryonated ova are also important. There is no vaccine available until now (please refer to vaccine section). In the secondary level of prevention, mass chemotherapy among school-age children has been highly successful in its control.

\subsection{Environmental Occurrence and Persistence}

\subsection{Detection Methods in the Environment}

The detection of ova in the environment remains a challenge due to the diluted concentrations with which they are found in sludge, biosolids or wastewater. Novel methods for detection have been developed based on biomolecular diagnosis like PCR. Nevertheless, these methods may not be able to differentiate between viable and non-viable ova. The US Environmental Protection Agency (EPA) has developed their own standard method based on a process of sedimentation, flotation, isolation and incubation of ova (EPA, 1999). Additional similar techniques have been developed, including Membrane filter, Leeds I and Faust (Maya et al., 2006). A recent study comparing the US EPA, the Membrane Filter, Leeds I and Faust techniques concluded that US EPA was the most suitable to detect ova in drinking water and wastewater in Mexico (Maya et al., 2006). After filtration, specific identification of helminthes including Trichina spp. is done by standard microscopy techniques. Molecular techniques applied to environmental samples, collectively known as environmental DNA or eDNA, (Bass et al., 2015) have also been used to identify ova in sludge, including real-time polymerase chain reaction (RT-PCR), PCR, quantitative real-time PCR (RT-qPCR), nested PCR and loop-mediated isothermal amplification (LAMP) (Amoah et al., 2017; Bass et al., 2015). One of the main challenges for DNA techniques is the difficulty to extract the T. trichiura DNA from the hard shell of the ova. Kaisar et al. have proposed the use of ethanol for sample preservation and beadbeating procedure to extract the DNA from the ova shell (Kaisar et al., 2017). The primers most commonly used for PCR techniques to detect whipworms from dogs, pigs, non-humans primates and humans are: Tt_283F, Tt_358R' and Tt_308T_YY (Liu et al., 2013). Unfortunately, DNA techniques do not substantially improve the sensitivity of the traditional microscopic techniques mainly because of the in the preservation of samples and DNA extraction. More recently, innovative techniques have been proposed for ova detection including the use of a microfluidic chambers to isolate ova (Izurieta and Selvaganapathy,
2016) as well as the use of an analytical digital image system to identify ova from wastewater samples processed using the US EPA technique (Jimenez et al., 2016). This analytical digital image system is reported to have a $99 \%$ specificity with a $80-90 \%$ sensitivity (Jimenez et al., 2016). Finally, the use of low cytometry or droplet digital PCR (ddPCR) for the analysis, detection and/or identification of ova in environmental samples has been proposed although yet to be reported (Amoah et al., 2017).

\subsection{Data on Occurrence in the Environment}

Trichuris spp. eggs are unembryonated and not infectious when they are excreted. Therefore, direct person-to-person or animal-to-person transmission is not possible. Thus, trichurid eggs must develop in soil, biosolids, or sludge to become infective. Larval development depends on temperature, moisture, presence of solar light, and $\mathrm{pH}$ conditions in the soil, sludge or biosolids. If the temperature conditions are optimum (i.e. $28^{\circ} \mathrm{C} \pm 4^{\circ} \mathrm{C}$ ), first-stage larvae can be developed in 15 to 21 days. If temperature remains constant at $22^{\circ} \mathrm{C}$, larva development can take 54 days whereas development can take up to 7 months if the temperature fluctuates between $6^{\circ} \mathrm{C}$ and $22^{\circ} \mathrm{C}$. In the soil, T. trichiura, T. vulpis and T. suis eggs usually remain viable for one year. However, in certain circumstances the eggs can remain viable for years. Humans probably become infected with the anthropozoonotic Trichuris spp. (i.e. swine or canine trichurid parasites) by ingesting contaminated soil or water (Faust, 1949; Bundy and Cooper, 1990).

\subsubsection{Raw sewage and sludge}

As explained earlier, Trichuris spp. eggs are excreted in feces and they need soil or soil-like storage conditions to achieve its infective embryonated stage. Afterwards, soilembryonated ova may access the human gastrointestinal track through ingestion of contaminated food or water. Consumption of raw vegetables that were irrigated by contaminated water has been described as one of the main mechanisms of transmission. In fact, it has been reported that sewage-contaminated water containing human and animal feces used to irrigate vegetables -estimated to be at least 20 million hectares in 50 countries- cause high prevalence of helminth infections in countries deficient wastewater treatment before it is discharged into rivers, ponds, and lakes (Duedu et al., 2014; Klapec and Borecka, 2012; Kozan et al., 2005).

For instance, a field study evaluating the presence of helminth ova in vegetable samples and which was carried out in Mazandaran province, northern Iran, reported any helminth species $14.95 \%$ of samples whereas Trichuris spp. ova were found in $2.2 \%$ of samples. The amount of Trichuris spp. ova found per $200 \mathrm{~g}$ of vegetable was 14 in parsley, 13 in lettuce, 9 in spinach, 8 in mint, 7 in radish, and 4 in green onion. The most likely source of contamination in this study was believed to be sewage effluent contaminating river water that is used for vegetable irrigation (Rostami et al., 2016). 


\subsubsection{Surface water}

Although it is possible that unsafe drinking water contaminated with soil or feces may carry Trichuris trichiura eggs, these ova are not normally found in piped drinking water systems that are properly maintained. The finding of T. trichiura eggs in drinking water is an eventual finding since they are usually removed during the process of decantation and filtration. Nevertheless, eggs may survive in decanted sediments of rivers ponds and lakes (WHO, 2004).

\subsubsection{Ground waters and drinking waters}

Protected aquifers usually provide microbiological safe water. The probability of ground water contamination by $T$. trichiura eggs is meaningless considering that helminths eggs will be retained during the filtration process. Nevertheless, unprotected and shallow aquifers can be subject to contamination from wastewater discharges and feces containing T. trichiura eggs (WHO, 2004).

\subsubsection{Seawater and shellfish}

Most wastewater that would possibly contain $T$. trichiura eggs is discharged into the ocean, oftentimes close to cities and recreational areas. In fact, a recent study reported that more than $90 \%$ of sewage water (approximately 550 megalitres a day in Cape Town, South Africa), which is likely to carry helminth eggs, reaches rivers and, afterwards, the ocean (Adams et al., 2005). The same study reported that helminth eggs might remain viable under the salinity conditions of seawater, (Adams et al., 2005) a hypothesis that has been otherwise proposed and which may have particular importance in island nations like Tuvalu (Speare et al., 2006).

\subsection{Persistence}

As observed with other geohelminths, warm, damp soil provides the best medium for transmission once it is contaminated with helminth-laden feces. Models of environmental data show that, after controlling for sanitation infrastructure and socioeconomic conditions, humidity, temperature, and $\mathrm{pH}$ are associated with $T$. trichiura transmission. Altogether these models suggest that although there may be transmission in template areas, intense transmission occurs mostly in tropical areas. Most likely, this observed hyperendemic transmission in tropical areas is associated with favorable conditions for ova development in soil. Only after ova has been embryonated in soil or soil-like surfaces, water has a role as a vehicle of transmission. Consequently, non-potable water containing embryonated ova as well as vegetables irrigated with untreated sewage water are main pathways of transmission in developing countries. As mentioned earlier, Trichuris trichiura has been reported in humans and non-human primates and therefore both human and non-human primates act as animal reservoirs whereas other zoonotic trichurid parasites can occasionally infect humans. The role of soil as reservoir has previously been suggested and described. Soils with warm temperatures (i.e. between $28^{\circ} \mathrm{C}$ and $35^{\circ} \mathrm{C}$ ) are ideal locations for egg embryonation. On the contrary, temperatures over $35^{\circ} \mathrm{C}$ (Moe and Izurieta, 2003) and below $-80^{\circ} \mathrm{C}$ (Despommier et al., 1995) destroy eggs.

Infective first stage larvae develop within the egg/shell in 3 to 8 weeks, depending on environmental temperature. The infective egg-encased first stage larvae are highly resistant and can remain in this form for several years in favorable conditions.

\subsection{Reductions by Sanitation Management}

\subsection{Wastewater Treatment}

Wastewater has been widely reused for agricultural purposes for a long period of time, especially in developing nations where the need for irrigation surpasses water supply leading to reuse of low quality (i.e. inappropriately treated) wastewater (Maya et al., 2010; Jimenez et al., 2016). Ova concentration in wastewater has been reported to range from 1 (in the United States) to 840 (in Morocco) per liter whereas helminth ova concentration has been reported to range from <1 (in Germany) to 735 (in Egypt) per gram of total solids in sludge (Table 2) (Jimenez, 2007). Helminth eggs present in wastewater can reach soil or crops where the temperature and humidity conditions might be ideal for their development into infective stages (Maya et al., 2010). In wastewater, helminth eggs are the human pathogens most resistant to inactivation during sludge and wastewater treatment (Maya et al., 2012). In addition, helminth eggs are characterized for their high infectiousness (usually one egg can establish infection) and their resistance to commonly used disinfection and/or inactivation techniques (Jimenez et al., 2016). In fact, helminth ova have been characterized as the greatest health risk in wastewater reused for agriculture and aquaculture (Maya et al., 2006; Jimenez, 2007). Accordingly, two out of three main helminth transmission mechanisms are related to wastewater effluent quality (namely ingestion of contaminated crops and direct contact with contaminate wastewater) (Jimenez, 2007). Once they reach crops, helminth eggs can survive for several months, even years; similar to the survivorship observed in water or soil (Jimenez, 2007). This represents both an urgent need and an opportunity we should not miss, especially if we consider that at least $10 \%$ of the irrigated land in developing nations, which roughly translates into 20 million ha, is estimated to be irrigated with low quality water (Jimenez et al., 2016). As per World Health Organization (WHO) guidelines, helminth eggs should be found at a concentration of $1 \mathrm{egg} / \mathrm{L}$ or less for wastewater irrigation reuse (Jimenez et al., 2016; Maya et al., $2006,2012)$. Therefore, the use of proper wastewater treatment techniques is required to ensure that high quality wastewater (effluents) is available for reuse in agriculture and aquaculture. Given the high temperature/low humidity requirements and the estimated relative long time required for inactivation, the goal in wastewater treatment should be helminth ova removal rather than inactivation (Jimenez, 2007). 
Table 2. HO concentration in wastewater and sludge. Source: Slightly modified from (Jimenez, 2007)

\begin{tabular}{lcc}
\hline \multicolumn{1}{c}{ Country/Region } & $\begin{array}{c}\text { Wastewater } \\
\text { (Ova per Liter) }\end{array}$ & $\begin{array}{c}\text { Sludge } \\
\text { (Ova per gTS) }\end{array}$ \\
\hline Mexico & 6 to 330 & 73 to 177 \\
Brazil & 166 to 202 & 75 \\
Egypt & $\mathrm{ND}^{\mathrm{a}}$ & Mean: $67 ;$ Max: 735 \\
Ghana & $\mathrm{ND}$ & 76 \\
Morocco & 840 & ND \\
Jordan & 300 & ND \\
Ukraine & 60 & ND \\
United States & 1 to 8 & 2 to 13 \\
France & 9 & 5 to 7 \\
Germany & $\mathrm{ND}$ & $<1$
\end{tabular}

${ }^{\mathrm{a}} \mathrm{ND}$ : Non-detect

Appropriate wastewater treatment may significantly reduce the presence of trichurid parasites. A recent report evaluated Trichuris trichiura ova inactivation under different physicochemical conditions using spiked sludge samples. In that study it was observed that Trichuris trichiura ova inactivation was directly correlated with increases in temperature, humidity, and $\mathrm{pH}$. For instance, Trichuris trichiura ova inactivation at $95 \%, 90 \%$ and $80 \%$ humidity is shown in Figure 7, Figure 8 and Figure 9, respectively (Adapted from Maya et al., 2010). This study also demonstrated that, under laboratory conditions, Trichuris trichiura eggs are more vulnerable than those of Ascaris (Maya et al., 2010).

\subsubsection{Composting of fecal wastes}

Trichuris spp. ova can be inactivated by manipulating specific storage conditions. Temperatures above $35^{\circ} \mathrm{C}$ and below $-80^{\circ} \mathrm{C}$ can inactivate the eggs and impede their maturation into infective embryonated forms (Moe and Izurieta, 2003; Despommier et al., 1995). Based on results from field experimental studies done with Ascaris lumbricoides ova, it can be inferred that desiccation or alcalinization do not have the capacity to inactivate Trichuris spp. ova in biosolids or in the environment (Moe and Izurieta, 2003; Mehl et al., 2011; Corrales et al., 2006).

\subsubsection{Wastewater treatment facilities}

Wastewater treatment is a complex process by which effluents are produced with different levels of quality. Primary wastewater treatment consists on the removal of coarse (settleable) solids and large materials through sedimentation, usually with a $25-50 \%$ reduction in biochemical oxygen demand (BOD), 50-70\% reduction in total suspended solids (TSS), and a 65\% reduction in oil and grease (Pescod, 1992). Secondary treatment is applied to primary treatment effluents to remove residual organics and suspended solids (Pescod, 1992). Tertiary treatment, also known as advanced treatment, is used to remove specific components not removed by the previous treatment methods (Pescod, 1992). Table 3 summarizes the main wastewater treatment methods and their important helminth ova removal characteristics.

Table 3. Wastewater treatment methods for generic helminth ova removal. Source: (Jimenez, 2007)

\begin{tabular}{|c|c|c|c|c|}
\hline Method & HO Removal Rate & Retention Time & $\begin{array}{l}\text { HO Effluent Concentration } \\
(\mathrm{HO} / \mathrm{L})^{\mathrm{a}} \\
\end{array}$ & Comments / Observations \\
\hline $\begin{array}{l}\text { Wastewater } \\
\text { Stabilization } \\
\text { Ponds (SP) }\end{array}$ & $>2 \log _{10}$ & 5 to 20 days & $\mathrm{NR}^{\mathrm{b}}$ & $\begin{array}{l}\text { Most suitable for } \\
\text { agriculture } \\
\text { Preferred method in } \\
\text { developing nations }\end{array}$ \\
\hline $\begin{array}{l}\text { Reservoirs } \\
\& \text { Dams }\end{array}$ & $>2 \log _{10}{ }^{\mathrm{c}}$ & $>20$ days & NR & $\begin{array}{l}\text { Useful when wastewater is } \\
\text { constant but crop water } \\
\text { demand is variable }\end{array}$ \\
\hline Wetlands & $>2 \log _{10}$ & 4 days? & NR & $\begin{array}{l}\text { Add horizontal flow gravel } \\
\text { bed ( } 25 \mathrm{~m} \text { length) }\end{array}$ \\
\hline
\end{tabular}




\begin{tabular}{|c|c|c|c|c|}
\hline Method & HO Removal Rate & Retention Time & $\begin{array}{l}\text { HO Effluent Concentration } \\
(\text { (HO / L) } \\
\end{array}$ & Comments / Observations \\
\hline $\mathrm{UASB}^{\mathrm{d}}$ & $>2 \log _{10}$ & 5.5 hour & 16 & $\begin{array}{l}\text { Recommended as a } \\
\text { complement to SP }\end{array}$ \\
\hline $\mathrm{CEPT}^{\mathrm{e}}$ & NR & 4 to 6 hours & $<1$ to 3 & $\begin{array}{l}\text { Effluent improves soil } \\
\text { productivity }\end{array}$ \\
\hline $\mathrm{APT}^{\mathrm{f}}$ & 1 to $2 \log _{10}$ & 0.5 to 1 hour & $<1$ to 3 & $\begin{array}{l}\text { Effluent improves soil } \\
\text { productivity }\end{array}$ \\
\hline $\begin{array}{l}\text { Rapid } \\
\text { filtration }\end{array}$ & 1 to $2 \log _{10}$ & $\begin{array}{l}7 \text { to } 10 \mathrm{~m}^{3} / \mathrm{m}^{2} / \mathrm{h} \\
\text { filtration rate }\end{array}$ & $<1.0$ & $\begin{array}{c}\text { Filter: } 0.8 \text { to } 1.2 \mathrm{~mm}, 1 \mathrm{~m} \\
\text { depth }\end{array}$ \\
\hline
\end{tabular}

${ }^{a}$ Varies depending on initial concentration; ${ }^{b} \mathrm{NR}$ : Not Reported; ${ }^{\mathrm{c} I f}$ operated as batch systems; ${ }^{\mathrm{d} U A S B}$ : Upflow anaerobic sludge blanket; ${ }^{\mathrm{e}} \mathrm{CEPT}$ : Chemical Enhanced Primary Treatment; ${ }^{\mathrm{f}} \mathrm{APT}$ : Advanced Primary Treatment

Pathogen (i.e. viruses, bacteria, protozoan and metazoan) removal from septic tanks can be primarily achieved through sedimentation (Pescod, 1992). Specifically, helminth ova may be more easily removed because of their weight and size (i.e. a high percentage of the ova will settle). The settling velocity of Trichuris spp. ova has been estimated to be 1.53 meters per hour, which is faster than that of Ascaris spp. at 0.65 meters per hour but slower than that of Taenia spp., which stands at 2 meters per hour (Amoah et al., 2017). However, the small fraction of unsettled helminth ova can survive adverse environmental conditions (e.g. temperature, $\mathrm{pH}$, chemical substances), which would otherwise inactivate other septic tank pathogens like viruses and bacteria (Jimenez, 2007).

There are several secondary and tertiary wastewater treatment procedures that can be applied to remove helminth ova/eggs from primary treatment effluents and, thus, improve compliance with national and international wastewater quality standards. Pescod (1992) classifies these treatments according to their performance into poor, fair or good helminth ova remover. Package Plant, Extended Aeration Activated Sludge and Biological Filter techniques have poor helminth ova removing performance whereas Activated Sludge Plant, Oxidation Ditch and Aerated Lagoon methods are fair removers and Waste Stabilization Pond Systems deemed to be good (highest level) helminth ova removers (Pescod, 1992).

\subsubsection{Wastewater secondary/natural treatment}

\subsubsection{Wastewater stabilization ponds and reservoirs}

Wastewater stabilization ponds (WSP) have been characterized both as the most suitable wastewater treatment technique for effluent reuse in agriculture and as the preferred wastewater treatment method in developing countries where land cost is reasonable and skill labor lacking (Pescod, 1992). Wastewater stabilization ponds significantly improve removal of bacteria, viruses and protozoa/helminth as compared to conventional methods (Jimenez, 2007). Specifically, stabilization ponds are reported to remove up to $>2 \log _{10}$ of helminth ova compared to 1 to $2 \log _{10}$ removed using conventional processes
(Jimenez, 2007). Among the several factors leading to this improved removal rate, sedimentation seems to play the most important role (Jimenez, 2007). Retention time to remove helminth ova varies from 5 to 20 days depending on the initial concentration, with majority of ova being retained in the first anaerobic pond (Jimenez, 2007). Similarly, reservoirs and dams are reported to remove helminth ova after $>20$ days retention time (Jimenez, 2007). Egg removal percentage in WSPs can be calculated by sequentially applying the equation below to each pond in the system:

\section{Equation 1. Egg removal percentage per each sequential pond in Waste Stabilization Pond treatment facilities. Source: (Jimenez, 2007)}

$R=100(1-0.41 \mathrm{e}-0.49 \Theta+0.0085 \Theta(\exp 2))$, where $\Theta$ is the retention time

\subsubsection{Wetlands}

Wetlands are a type of Macrophyte Treatment System where aerobic and anaerobic treatment takes place and where BOD and nitrogen/phosphorus/heavy metals are removed by bacterial activity (Pescod, 1992, Jimenez, 2007). Wetlands are reported to remove 0.4 to $>2 \log _{10}$ of protozoans, especially when using a 4-day retention time, whereas $>2 \log _{10}$ helminth ova removal can be achieved by adding a horizontal flow gravel bed in a $25 \mathrm{~m}$ length (Jimenez, 2007).

\subsubsection{Upflow anaerobic sludge blanket (UASB)}

Upflow anaerobic sludge blanket (UASB) has been recommended as a complimentary technique to stabilization ponds (Jimenez, 2007). The UASB method uses sedimentation and sludge bed filtration to remove helminth ova (Jimenez, 2007). It has been reported that UASB used with a 5.5-hour retention time produced an effluent containing a mean of 16 helminth ova /L (1.3-45 helminth ova /L) when wastewater containing 64-320 helminth ova /L was used, which represents a $1.3 \log _{10}$ removal efficiency (Jimenez, 2007). 


\subsubsection{Wastewater tertiary treatment}

In order to raise the quality of the effluent, a wastewater tertiary treatment can be applied. This tertiary wastewater treatment can be accomplished by a variety of methods such as coagulation-sedimentation, filtration, reverse osmosis, and secondary biological treatment to further stabilize oxygen-demanding substances or remove nutrients. In various combinations, these processes can attain any desired degree of pollution control. As the effluent wastewater is purified to higher levels of quality, it can then be reused for: 1) urban, landscape, and/or agricultural irrigation; 2) industrial cooling and processing; 3) recreational uses and water recharge; and, even, 4) indirect and direct augmentation of drinking water supplies (Drechsel, 2010).

\subsubsection{Coagulation and flocculation}

Coagulation and flocculation are important processes derived from ancient techniques and used for drinking water and wastewater treatment (Bratby, 2016). Chemicals can be added to this technique in order to increase the settling velocity of helminth ova (Jimenez, 2007). Chemical Enhanced Primary Treatment (CEPT) refers to the addition of low coagulant doses and high molecular weight / high density charge flocculants to the coagulation-flocculation processes whereas Advanced Primary Treatment (APT) refers to the use of a high rate settler as opposed to a conventional one when conducting CEPT (Jimenez, 2007). Both APT and CEPT achieve an effluent with low concentration of suspended solids and helminth ova while retaining organic matter, nitrogen and phosphorus in the dissolved fraction, (Jimenez, 2007) and probably some other pathogens. This translates into an effluent that improves soil productivity but which still requires disinfection (either UV light or chlorine) to inactivate bacteria (Jimenez, 2007). It has been estimated that effluents with $20-40 \mathrm{mg}$ TSS/L contain around 3-10 helminth ova / L whereas effluents with < 20, mg TSS / L contain less than 1 helminth ova / L (Jimenez, 2007). Retention times vary from 0.5-1 hour for APT to 4-6 hours for CEPT (Jimenez, 2007). A 1 to $2 \log _{10}$ helminth ova removal can be achieved with APT (Jimenez, 2007).

\subsubsection{Filtration}

Filtration can successfully remove Trichuris spp. from effluents of primary or secondary treatment (Landa et al., 1997). For instance, a recent study comparing three macrofiltration methods (namely, Disc Filter, Mesh Filter and Pressure Sand Filter) found that all of them efficiently removed all pathogenic nematode eggs from secondary clarification water samples (Gómez et al., 2010). Pressure
Sand Filter was not only the most efficient in terms of improved turbidity and concentration of suspended solids $(p<0.0001)$ but also the least expensive technique. For non-pathogenic nematode eggs, however, there was only an important reduction in concentration (as opposed to the complete absence observed for pathogenic nematodes), suggesting that there could still be a possibility to recover human pathogenic nematodes after macrofiltration (Gómez et al., 2010). Further research is required to completely rule out the presence of pathogenic nematodes in instances of secondary clarification followed by macrofiltration (Gómez et al., 2010). Nonetheless, these results are encouraging, especially if we consider that nematode eggs are resistant to UV irradiation and disinfection and therefore another step would be required before UV irradiation/disinfection are applied to wastewater if we are to prevent the presence of viable nematode eggs in effluent waters (Gómez et al., 2010). Macrofiltration methods might very well fit this description, as shown by Gómez, et al. (2010). In addition, rapid filtration ( $>2 \mathrm{~m} / \mathrm{h}$ ) has been shown to remove 1 to $2 \log _{10}$ of helminth ova, a removal that can be increased by 2 to $4 \log _{10}$ with the addition of coagulants (Jimenez, 2007). Rapid sand filtration with a specific size of 0.8-1.2 mm, a minimal filter depth of $1 \mathrm{~m}$ and filtration rates of $7-10 \mathrm{~m} 3 / \mathrm{m} 2 / \mathrm{h}$ yield effluents with constant helminth ova concentration of $<1.0 / \mathrm{L}$ (Jimenez, 2007).

\subsubsection{Reverse osmosis}

Recently, a novel pig manure treatment method termed AMAK and which included pressure filtration as it final step reported Trichuris spp.-free effluents (Makara and Kowalski, 2015).

\subsection{Disinfection}

3.2.1 Chemical disinfection with lime, urea, chlorine, and ozone

Lime $(\mathrm{CaO})$, a pH increasing agent, has been used in sludge pathogen inactivation (Maya et al., 2010; MignotteCadiergues et al., 2001). A recent study reported that total inactivation of Trichuris trichiura ova can be achieved at different rates depending on specific storage conditions; namely, $\mathrm{CaO}$ concentration and humidity (Table 4). In general terms, increasing $\mathrm{CaO}$ concentrations and/or decreasing humidity are associated with reduction in the time to achieve total Trichuris trichiura ova inactivation.

In other studies, ammonia and $\mathrm{CaO}$ have been applied in sludge of open and closed systems. Ammonia was able to remove up to $1.4 \log _{10}$ of viable helminth ova (Mendez et al., 2002). 
Table 4. Time to T. trichiura ova inactivation under different $\mathrm{CaO}$ concentration and humidity conditions. Source: Created based on data reported by ( Maya et al., 2010 )

\begin{tabular}{ccc}
\hline CaO Concentration & Humidity & Storage Time to Total Inactivation of T. trichiura Ova \\
\cline { 3 - 3 } $15 \%$ & $90 \%$ & After 6 months \\
$20 \%$ & $80 \%$ & 4 months \\
$20 \%$ & $90 \%$ & After 4 months \\
& $80 \%$ & 2 months
\end{tabular}

\subsubsection{Irradiation and UV disinfection}

Trichuris spp. eggs are destroyed by dehydration and sunlight. T. trichiura eggs die above $52^{\circ} \mathrm{C}$ or below $-9^{\circ} \mathrm{C}$. In the laboratory, T. muris eggs can be inactivated with $30 \%$ (v/v) ammonia, combined with temperatures greater than $30^{\circ} \mathrm{C}$ (The Center for Food Security and Public Health,

Table 5. Trichuris trichiura inactivation under varying conditions in the laboratory ${ }^{\text {a }}$

\begin{tabular}{lcccc}
\hline \multirow{2}{*}{ Dryness } & \multicolumn{2}{c}{ Non-larval } & \multicolumn{2}{c}{ Larval } \\
\cline { 3 - 5 } \cline { 5 - 5 } & Contact Time (min) & Temperature (oC) & Contact Time (min) & Temperature (oC) \\
\hline $5 \%$ & 120 & $78-80$ & 30 & 70 \\
$5 \%$ & 180 & $70-73$ & 60 & 60 \\
$10 \%$ & 120 & $70-73$ & 30 & 60 \\
$10 \%$ & 180 & 70 & -- & -- \\
$20 \%$ & 120 & $66-70$ & 30 & 60 \\
$20 \%$ & 180 & 63 & -- & --
\end{tabular}

${ }^{\text {a }}$ Data derived from (Maya et al., 2012)

\subsubsection{Biological control by predators}

Predatory fungi have been evaluated for it
2005). A recent study reported that inactivation of six helminth species, including Trichuris trichiura, can be achieved within 6 days at $45^{\circ} \mathrm{C}, 5.3 \mathrm{pH}$ and $90 \%$ dryness (Maya et al., 2012). Helminth egg/ova inactivation is a function of these conditions (i.e. temperature, $\mathrm{pH}$, dryness and time). Table 5 shows the conditions required to inactivate $>2 \log _{10}$ of $T$. trichiura in laboratory experiments. Among all studied helminths, Trichuris trichiura and $H$. nana were the least resistant parasites (Maya et al., 2012).

nematophagous activity against Trichuris trichiura eggs. Pochonia chlamydosporia isolates (VC1 and VC4) were found to have a role in destroying Trichuris trichiura eggs after the 6 hours of observation (Silva et al., 2010, 2011) (Figure 10). Consequently, these fungi could be used as possible biological controls of Trichuris trichiura.
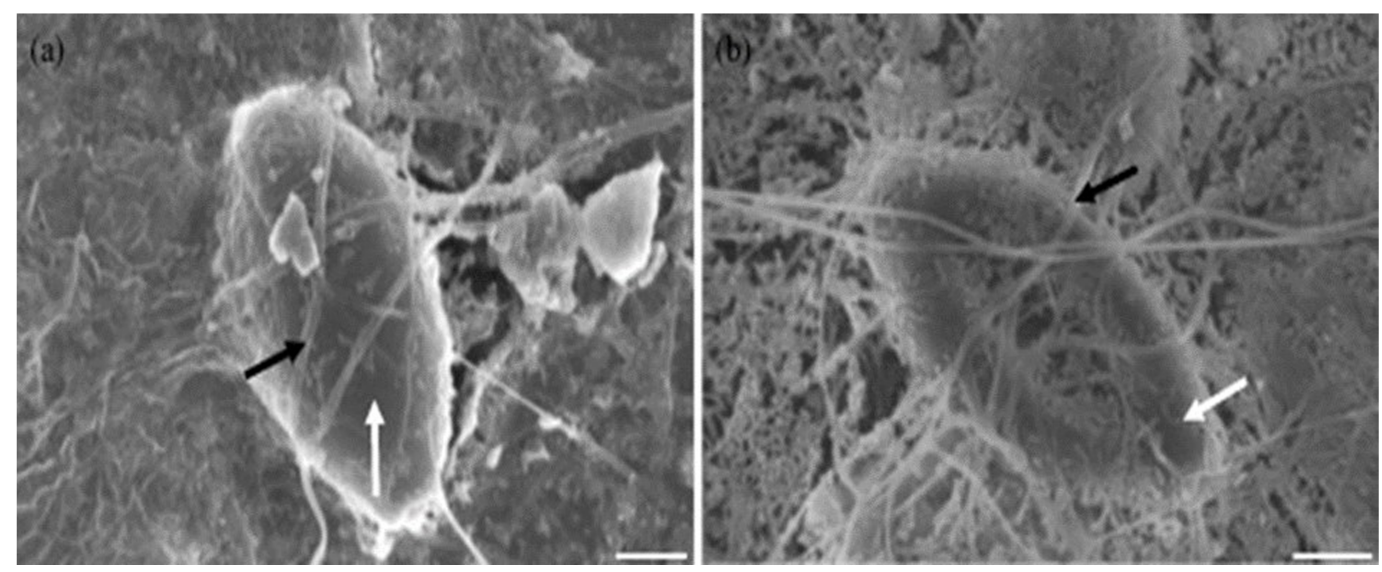

Figure 10. Destruction of Trichuris trichiura eggs (white arrowx) after the 6-h observation period by isolates of Pochonia chlamydosporia (VC1 and VC4) (black arrow). SEM. Bar: (a) 10 нm; (b) $10 \mu \mathrm{m}$. 


\section{References}

Adams, V.J., Markus, M.B., Adams, J.F., Jordaan, E., Curtis, B., Dhansay, M.A. et al. (2005). Paradoxical helminthiasis and giardiasis in Cape Town, South Africa: epidemiology and control. African Health Sciences. 5, pp. 131-6.

Al-Mekhlafi, M.S., Azlin, M., U. Aini, N., Shaikh, A., Sa'iah, A., Fatmah, M.S. et al. (2006). Prevalence and distribution of soil-transmitted helminthiases among Orang Asli children living in peripheral Selangor, Malaysia. Southeast Asian Journal of Tropical Medicine and Public Health. 37, pp. 40-7.

Albonico, M., Bickle, Q., Haji, H.J., Ramsan, M., Khatib, K.J., Montresor, A. et al. (2002). Evaluation of the efficacy of pyrantel-oxantel for the treatment of soil-transmitted nematode infections. Transactions of the Royal Society of Tropical Medicine and Hygiene. 96, pp. 685-90.

Amoah, I.D., Singh, G., Stenström, T.A. and Reddy, P. (2017). Detection and quantification of soil-transmitted helminths in environmental samples: A review of current state-of-the-art and future perspectives. Acta Tropica. 169, pp. 187-201.

Anuar, T.S., Salleh, F.M. and Moktar, N. (2014). Soil-transmitted helminth infections and associated risk factors in three Orang Asli tribes in Peninsular Malaysia. Scientific reports. 4, pp. 4101.

Bass, D., Stentiford, G.D., Littlewood, D.T. and Hartikainen, H. (2015). Diverse Applications of Environmental DNA Methods in Parasitology. Trends in Parasitology. 31, pp. 499-513.

Bennett, A. and Guyatt, H. (2000). Reducing intestinal nematode infection: efficacy of albendazole and mebendazole. Parasitology Today. 16, pp. 71-4.

Bethony, J., Brooker, S., Albonico, M., Geiger, S.M., Loukas, A., Diemert, D. et al. (2006). Soil-transmitted helminth infections: ascariasis, trichuriasis, and hookworm. Lancet. 367, pp. 1521-32.

Bratby, J. (2016). Coagulation and flocculation in water and wastewater treatment. 3rd ed. pp. xii, 524 pages.

Bundy, D.A.P. and Cooper, E.S. (1990). Chapter 46. Trichuriasis. In: Warren, Kenneth S. \&amp; Mahmoud, Adel A. F.Tropical and geographical medicine. 2nd ed. McGraw-Hill. New York. pp. xviii, 1159 p.

Callejon, R., Gutierrez-Aviles, L., Halajian, A., Zurita, A., de Rojas, M. and Cutillas, C. (2015). Taxonomy and phylogeny of Trichuris globulosa Von Linstow, 1901 from camels. A review of Trichuris species parasitizing herbivorous. Infection, Genetics and Evolution. 34, pp. 61-74.

CDC (2016). DPDx - Laboratory Identification of Parasitic Diseases of Public Health Concern. 2017, Centers for Disease Control and Prevention. Atlanta, Georgia.

Cook, G. and Zumla, A. (2003). Manson's tropical diseases. 21st ed. W. B. Saunders. London. pp. xiii, 1847 p.

Cooper, P.J., Chico, M.E., Guadalupe, I., Sandoval, C.A., Mitre, E., Platts-Mills, T.A. et al. (2011). Impact of early life exposures to geohelminth infections on the development of vaccine immunity, allergic sensitization, and allergic inflammatory diseases in children living in tropical Ecuador: the ECUAVIDA birth cohort study. BMC Infectious Diseases. 11, pp. 184.

Corrales, L.F., Izurieta, R. and Moe, C.L. (2006). Association between intestinal parasitic infections and type of sanitation system in rural El Salvador. Tropical Medicice and International Health. 11, pp. 1821-31.

De Carneri, I., Gazzola, E. and Biagi, F. (1971). Repeated infestations, presumable, of Trichuris vulpis in a child living in an endemic region of trichocephalosis. Rivista di Parassitologia. 32, pp. 135-6.

Despommier, D.D., Gwadz, R.W. and Hotez, P.J. (1995). Parasitic diseases. 3rd ed. Springer-Verlag. New York. pp. xii, 333 p., 4 p. of plates.

Diemert, D.J., Pinto, A.G., Freire, J., Jariwala, A., Santiago, H., Hamilton, R.G. et al. (2012). Generalized urticaria induced 
by the Na-ASP-2 hookworm vaccine: implications for the development of vaccines against helminths. The Journal of Allergy and Clinical Immunology. 130, pp. 169-76 e6.

Disease, G.B.D., Injury, I. and Prevalence, C. (2016). Global, regional, and national incidence, prevalence, and years lived with disability for 310 diseases and injuries, 1990-2015: a systematic analysis for the Global Burden of Disease Study 2015. Lancet. 388, pp. 1545-1602.

Dixon, H., Johnston, C.E. and Else, K.J. (2008). Antigen selection for future anti-Trichuris vaccines: a comparison of cytokine and antibody responses to larval and adult antigen in a primary infection. Parasite Immunology. 30, pp. 454-61.

Dixon, H., Little, M.C. and Else, K.J. (2010). Characterisation of the protective immune response following subcutaneous vaccination of susceptible mice against Trichuris muris. International Journal of Parasitology. 40, pp. 683-93.

Drechsel, P. (2010). Wastewater irrigation and health : assessing and mitigating risk in low-income countries. Earthscan. London ; Sterling, VA. pp. xxvi, 404 p.

Duedu, K.O., Yarnie, E.A., Tetteh-Quarcoo, P.B., Attah, S.K., Donkor, E.S. and Ayeh-Kumi, P.F. (2014). A comparative survey of the prevalence of human parasites found in fresh vegetables sold in supermarkets and open-aired markets in Accra, Ghana. BMC Research Notes. 7, pp. 836.

Dunn, J.J., Columbus, S.T., Aldeen, W.E., Davis, M. and Carroll, K.C. (2002). Trichuris vulpis recovered from a patient with chronic diarrhea and five dogs. Journal of Clinical Microbiology. 40, pp. 2703-4.

EPA (1999). Environmental Regulations and Technology: Control of Pathogens and Vector Attraction in Sewage Sludge. Environmental Protection Agency.

Faust, E.C. (1949). Human helminthology, a manual for physicians, sanitarians, and medical zoologists. 3d ed. Lea and Febiger. Philadelphia. pp. 744 p.

Figueiredo, C.A., Barreto, M.L., Rodrigues, L.C., Cooper, P.J., Silva, N.B., Amorim, L.D. et al. (2010). Chronic intestinal helminth infections are associated with immune hyporesponsiveness and induction of a regulatory network. Infection and Immunity. 78, pp. 3160-7.

Fitzpatrick, C. and Engels, D. (2016). Leaving no one behind: a neglected tropical disease indicator and tracers for the Sustainable Development Goals. International Health. 8 Suppl 1, pp. i15-8.

Giacomin, P., Croese, J., Krause, L., Loukas, A. and Cantacessi, C. (2015). Suppression of inflammation by helminths: a role for the gut microbiota?. Philosophical Transactions of the Royal Society B. 370,.

Gomez, M., Plaza, F., Garralon, G., Pérez, J. and Gómez, M.A. (2010). Comparative analysis of macrofiltration processes used as pre-treatment for municipal wastewater reuse. Desalination. 255, pp. 72-77.

Gorbach, S.L., Bartlett, J.G. and Blacklow, N.R. (1992). Infectious diseases. Saunders. Philadelphia. pp. xxxvi, 2115 p.

Guadagnini, R.A., Santos, L.U. dos, Franco, R.M. and Guimaraes, J.R. (2013). Inactivation of bacteria and helminth in wastewater treatment plant effluent using oxidation processes. Water Science and Technology. 68, pp. 1825-9.

Guerrant, R.L., Walker, D.H. and Weller, P.F. (2011). Tropical infectious diseases : principles, pathogens and practice. Third edition. ed. Saunders/Elsevier. Edinburgh. pp. xxiv, 1130 pages.

Hall, J.E. and Sonnenberg, B. (1956). An apparent case of human infection with the whipworm of dogs, Trichuris vulpis (Froelich, 1789). Journal of Parasitology. 42, pp. 197-9.

Hotez, P.J. (2009). Mass drug administration and integrated control for the world's high-prevalence neglected tropical diseases. Clinical Pharmacology and Therapeutics. 85, pp. 659-64.

Izurieta, R. (2016). WIPO Re: Search Novel Method to detect helminth ova in the environment. Accelerating R\&amp;D for Neglected Tropical Diseases through Global Collaborations. WIPO Re:Search Partnership Stories 2013-2015. 
Jimenez, B. (2007). Helminth ova removal from wastewater for agriculture and aquaculture reuse. Water Science and Technology. 55, pp. 485-93.

Jimenez, B., Maya, C., Velasquez, G., Torner, F., Arambula, F., Barrios, J.A. et al. (2016). Identification and quantification of pathogenic helminth eggs using a digital image system. Experimental Parasitology. 166, pp. 164-72.

Jung, R.C. and Beaver, P.C. (1951). Clinical observations on Trichocephalus trichiurus (whipworm) infestation in children. Pediatrics. 8, pp. 548-57.

Kagei, N., Hayashi, S. and Kato, K. (1986). Human cases of infection with canine whipworms, Trichuris vulpis (Froelich, 1789), in Japan. Japanese Journal of Medical Science and Biology. 39, pp. 177-84.

Kaisar, M.M.M., Brienen, E.A.T., Djuardi, Y., Sartono, E., Yazdanbakhsh, M., Verweij, J.J. et al. (2017). Improved diagnosis of Trichuris trichiura by using a bead-beating procedure on ethanol preserved stool samples prior to DNA isolation and the performance of multiplex real-time PCR for intestinal parasites. Parasitology. 144(7), pp. 965-974.

Keiser, J. and Utzinger, J. (2008). Efficacy of current drugs against soil-transmitted helminth infections: systematic review and meta-analysis. JAMA. 299, pp. 1937-48.

Kepha, S., Mwandawiro, C.S., Anderson, R.M., Pullan, R.L., Nuwaha, F., Cano, J. et al. (2017). Impact of single annual treatment and four-monthly treatment for hookworm and Ascaris lumbricoides, and factors associated with residual infection among Kenyan school children. Infectious Diseases of Poverty. 6, pp. 30.

Ketzis, J.K. (2015). Trichuris spp. infecting domestic cats on St. Kitts: identification based on size or vulvar structure? Springerplus. 4, pp. 115.

Klapec, T. and Borecka, A. (2012). Contamination of vegetables, fruits and soil with geohelmints eggs on organic farms in Poland. Annals of Agricultural and Environmental Medicine. 19, pp. 421-5.

Knopp, S., Mohammed, K.A., Speich, B., Hattendorf, J., Khamis, I.S., Khamis, A.N. et al. (2010). Albendazole and mebendazole administered alone or in combination with ivermectin against Trichuris trichiura: a randomized controlled trial. Clinical Infectious Diseases. 51, pp. 1420-8.

Kozan, E., Gonenc, B., Sarimehmetoglu, O. and Aycicek, H. (2005). Prevalence of helminth eggs on raw vegetables used for salads. Food Control. 16, pp. 239-242.

Kuntz, R.E. and Meyers, B.J. (1966). Parasites of baboons (Papio doguera [Pucheran, 1856]) captured in Kenya and Tanzania, East Africa. Primates. 7, pp. 27-32.

Landa, H., Capella, A. and Jimenez, B. (1997). Particle size distribution in an efluent from an advanced primary treatment and its removal during filtration. Water Science and Technology. 36, pp. 159-165.

Levecke, B., Buttle, D.J., Behnke, J.M., Duce, I.R. and Vercruysse, J. (2014). Cysteine proteinases from papaya (Carica papaya) in the treatment of experimental Trichuris suis infection in pigs: two randomized controlled trials. Parasites and Vectors. 7, pp. 255.

Levecke, B., Montresor, A., Albonico, M., Ame, S.M., Behnke, J.M., Bethony, J.M. et al. (2014). Assessment of anthelmintic efficacy of mebendazole in school children in six countries where soil-transmitted helminths are endemic. PLOS Neglected Tropical Diseases. 8, pp. e3204.

Lineburg, A. and Jastrzebski, M. (1987). [A case of infestation with Trichuris (Trichocephalus vulpis Froelich, 1789 (Nematoda, Enoplida) in Poland]. Wiadomości parazytologiczne. 33, pp. 181-4.

Liu, G.H., Gasser, R.B., Nejsum, P., Wang, Y., Chen, Q., Song, H.Q. et al. (2013). Mitochondrial and nuclear ribosomal DNA evidence supports the existence of a new Trichuris species in the endangered françois' leaf-monkey. PLos One. 8(6), pp. e66249.

Mackey, T.K., Liang, B.A., Cuomo, R., Hafen, R., Brouwer, K.C. and Lee, D.E. (2014). Emerging and reemerging neglected 
tropical diseases: a review of key characteristics, risk factors, and the policy and innovation environment. Clinical Microbiology Reviews. 27, pp. 949-79.

Makara, A. and Kowalski, Z. (2015). Pig manure treatment and purification by filtration. Journal of Environmental Management. 161, pp. 317-324.

Manser, N.D., Wald, I., Ergas, S.J., Izurieta, R. and Mihelcic, J.R. (2015). Assessing the fate of Ascaris suum ova during mesophilic anaerobic digestion. Environmental Science and Technology. 49, pp. 3128-35.

Markell, E.K., John, D.T. and Krotoski, W.A. (1999). Markell and Voge's medical parasitology. 8th ed. Saunders. Philadelphia ; London. pp. viii, 501 p.

Marquez-Navarro, A., Garcia-Bracamontes, G., Alvarez-Fernandez, B.E., Alvila-Caballero, L.P., Santos-Aranda, I., DiazChiguer, D.L. et al. (2012). Trichuris vulpis (Froelich, 1789) infection in a child: a case report. Korean Journal of Parasitology. 50, pp. 69-71.

Maya, C., Jimenez, B. and Schwartzbrod, J. (2006). Comparison of techniques for the detection of helminth ova in drinking water and wastewater. Water Environmental Research. 78, pp. 118-24.

Maya, C., Ortiz, M. and Jimenez, B. (2010). Viability of Ascaris and other helminth genera non larval eggs in different conditions of temperature, lime (pH) and humidity. Water Science and Technology. 62, pp. 2616-24.

Maya, C., Torner-Morales, F.J., Lucario, E.S., Hernandez, E. and Jimenez, B. (2012). Viability of six species of larval and non-larval helminth eggs for different conditions of temperature, pH and dryness. Water Research. 46, pp. 4770-82.

Mehl, J., Kaiser, J., Hurtado, D., Gibson, D.A., Izurieta, R. and Mihelcic, J.R. (2011). Pathogen destruction and solids decomposition in composting latrines: study of fundamental mechanisms and user operation in rural Panama. Journal of Water and Health. 9, pp. 187-99.

Melfi, V. and Poyser, F. (2007). Trichuris burdens in Zoo-Housed Colobus guereza. International Journal of Primatology. 28, pp. 1449-1456.

Mendez, J.M., Jimenez, B.E. and Barrios, J.A. (2002). Improved alkaline stabilization of municipal wastewater sludge. Water Science and Technology. 46, pp. 139-46.

Mignotte-Cadiergues, B., Maul, A., Huyard, A., Capizzi, S. and Schwartzbrod, L. (2001). The effect of liming on the microbiological quality of urban sludge. Water Science and Technology. 43, pp. 195-200.

Mirdha, B.R., Singh, Y.G., Samantray, J.C. and Mishra, B. (1988). Trichuris vulpis infection in slum children. Indian Journal of Gastroenterology. 17, pp. 154.

Moe, C. and Izurieta, R. (2003). Longitudinal study of double vault urine diverting toilets and solar toilets in El Salvador. 2nd International Symposium on Ecological Sanitation. Deutsche Gesellschaft für Technische Zusammenarbeit (GTZ) GmbH. Lübeck, Germany.

Myers, P., Espinosa, R., Parr, C.S., Jones, T., Hammond, G.S. and Dewey, T.A. (2017). The Animal Diversity Web. 2017, University of Michigan - Museum of Zoology.

Nejsum, P., Betson, M., Bendall, R.P., Thamsborg, S.M. and Stothard, J.R. (2012). Assessing the zoonotic potential of Ascaris suum and Trichuris suis: looking to the future from an analysis of the past. Journal of Helminthology. 86, pp. $148-55$.

Norhayati, M., Zainudin, B., Mohammod, C.G., Oothuman, P., Azizi, O. and Fatmah, M.S. (1997). The prevalence of Trichuris, Ascaris and hookworm infection in Orang Asli children. Southeast Asian Journal of Tropical Medicine and Public Health. 28, pp. 161-8.

Pescod, M.B. (1992). Wastewater treatment and use in agriculture. FAO irrigation and drainage paper. Food and Agriculture Organization of the United Nations. Rome. pp. xiv, 125 p. 
Platts-Mills, T., Vaughan, J., Squillace, S., Woodfolk, J. and Sporik, R. (2001). Sensitisation, asthma, and a modified Th2 response in children exposed to cat allergen: a population-based cross-sectional study. Lancet. 357, pp. 752-6.

Price, D. (1994). Procedure Manual for the Diagnosis of Intestinal Parasites. CRC Press Inc.

Pullan, R.L., Smith, J.L., Jasrasaria, R. and Brooker, S.J. (2014). Global numbers of infection and disease burden of soil transmitted helminth infections in 2010. Parasites and Vectors. 7, pp. 37.

Reina-Ortiz, M., Schreiber, F., Benitez, S., Broncano, N., Chico, M.E., Vaca, M. et al. (2011). Effects of chronic ascariasis and trichuriasis on cytokine production and gene expression in human blood: a cross-sectional study. PLOS Neglected Tropical Diseases. 5, pp. e1157.

Robinson, R.D., Thompson, D.L. and Lindo, J.F. (1989). A survey of intestinal helminths of well-cared-for dogs in Jamaica, and their potential public health significance. Journal of Helminthology. 63, pp. 32-8.

Rostami, A., Ebrahimi, M., Mehravar, S., V. Omrani, F., Fallahi, S. and Behniafar, H. (2016). Contamination of commonly consumed raw vegetables with soil transmitted helminth eggs in Mazandaran province, northern Iran. International Journal of Food Microbiology. 225, pp. 54-8.

Sanchez, A.L., Mahoney, D.L. and Gabrie, J.A. (2015). Interleukin-10 and soil-transmitted helminth infections in Honduran children. BMC Research Notes. 8, pp. 55.

Savioli, L., Engels, D. and Endo, H. (2005). Extending the benefits of deworming for development. Lancet. 365, pp. 1520-1.

Sharad, S.M., Maria, C.E.Ligia and Ricardo, I. (2012). A Novel Strategy for Environmental Control of Soil Transmitted Helminthes. Health and the Environment Journal. 3,.

Silva, A.R., Araujo, J.V., Braga, F.R., Alves, C.D. and Frassy, L.N. (2010). In vitro ovicidal activity of the nematophagous fungi Duddingtonia flagrans, Monacrosporium thaumasium and Pochonia chlamydosporia on Trichuris vulpis eggs. Veterinary Parasitology. 172, pp. 76-9.

Silva, A.R., Araujo, J.V., Braga, F.R., Benjamim, L.A., Souza, D.L. and Carvalho, R.O. (2011). Comparative analysis of destruction of the infective forms of Trichuris trichiura and Haemonchus contortus by nematophagous fungi Pochonia chlamydosporia; Duddingtonia flagrans and Monacrosporium thaumasium by scanning electron microscopy. Veterinary Microbiology. 147, pp. 214-9.

Speare, R., Latasi, F.F., Nelesone, T., Harmen, S., Melrose, W., Durrheim, D. et al. (2006). Prevalence of soil transmitted nematodes on Nukufetau, a remote Pacific island in Tuvalu. BMC Infectious Diseases. 6, pp. 110.

Speich, B., Ame, S.M., Ali, S.M., Alles, R., Huwyler, J., Hattendorf, J. et al. (2014). Oxantel pamoate-albendazole for Trichuris trichiura infection. The New England Journal of Medicine. 370, pp. 610-20.

Stephenson, L.S., Holland, C.V. and Cooper, E.S. (2000). The public health significance of Trichuris trichiura. Parasitology. 121 Suppl, pp. S73-95.

Stratton, K.R., Howe, C.J. and Johnston, Jr., R.B. (1994). Adverse Events Associated with Childhood Vaccines: Evidence Bearing on Causality. Adverse Events Associated with Childhood Vaccines: Evidence Bearing on Causality. (Stratton, K.R., Howe, C.J. and Johnston, Jr., R.B., ed.).

Summers, R.W., Elliott, D.E. and Weinstock, J.V. (2005). Why Trichuris suis should prove safe for use in inflammatory bowel diseases. Inflammatory bowel disease. 11, pp. 783-4.

The Center for Food Security and Public Health (2005). Trichuriasis. 2017, College of Veterinary Medicine, Iowa State University. Ames, Iowa.

Tun, S., Ithoi, I., Mahmud, R., Samsudin, N.I., C. Heng, K. and Ling, L.Y. (2015). Detection of Helminth Eggs and Identification of Hookworm Species in Stray Cats, Dogs and Soil from Klang Valley, Malaysia. PLoS One. 10, pp. e0142231. 
Urquhart, G.M., Dunn, A.M., Jennings, F.W., Duncna, J.L. and Armour, J. (1988). Veterinary Parasitology ELBS, Bath Press Avon Great Britain.

Vanparijs, O., Hermans, L. and van der Flaes, L. (1991). Helminth and protozoan parasites in dogs and cats in Belgium. Veterinary Parasitology. 38, pp. 67-73.

Wakelin, D. and Selby, G.R. (1973). Functional antigens of Trichuris muris. The stimulation of immunity by vaccination of mice with somatic antigen preparations. International Journal of Parasitology. 3, pp. 711-5.

Weinstock, J.V. and Elliott, D.E. (2009). Helminths and the IBD hygiene hypothesis. Inflammatory bowel disease. 15, pp. 128-33.

WHO (2004). Weekly epidemiological record. Cholera, 2003. 79, pp. 281-288.

WHO, W.Health Org (2016). Soil-trasnmitted helminth infections. Fact Sheet.

Williams-Blangero, S., McGarvey, S.T., Subedi, J., Wiest, P.M., Upadhayay, R.P., Rai, D.R. et al. (2002). Genetic component to susceptibility to Trichuris trichiura: evidence from two Asian populations. Genetic Epidemiology. 22, pp. 254-64.

Williams-Blangero, S., Vandeberg, J.L., Subedi, J., Jha, B., Dyer, T.D. and Blangero, J. (2008). Two quantitative trait loci influence whipworm (Trichuris trichiura) infection in a Nepalese population. The Journal of Infectious Diseases. 197, pp. 1198-203.

Wright, V.J., Ame, S.M., Haji, H.S., Weir, R.E., Goodman, D., Pritchard, D.I. et al. (2009). Early exposure of infants to GI nematodes induces Th2 dominant immune responses which are unaffected by periodic anthelminthic treatment. PLOS Neglected Tropical Diseases. 3, pp. e433.

Yang, Y., Wen, Y., Cai, Y.N., Vallee, I., Boireau, P., Liu, M.Y. et al. (2015). Serine proteases of parasitic helminths. Korean Journal of Parasitology. 53, pp. 1-11.

Yu, W., Ross, A.G., Olveda, R.M., Harn, D.A., Li, Y., Chy, D. et al. (2016). Risk of human helminthiases: geospatial distribution and targeted control. International Journal of Infectious Diseases.

Zhan, B., Beaumier, C.M., Briggs, N., Jones, K.M., Keegan, B.P., Bottazzi, M.E. et al. (2014). Advancing a multivalent 'Pananthelmintic' vaccine against soil-transmitted nematode infections. Expert Review of Vaccines. 13, pp. 321-31. 